\title{
Mechanistic Studies on the Stereoselective Formation of $\beta$-Mannosides from Mannosyl Iodides Using $\alpha$-Deuterium Kinetic Isotope Effects
}

\author{
Supporting Information
}

Mohamed H. El-Badri, Dan Willenbring, Dean J. Tantilllo* and Jacquelyn Gervay-Hague*

University of California, Davis, Department of Chemistry, One Shields

Avenue, Davis, California, 95616

Table of contents

${ }^{1} \mathrm{H}$ NMR of compound $\mathbf{5}$

${ }^{13} \mathrm{C}$ NMR of compound $\mathbf{5}$

${ }^{1} \mathrm{H}$ NMR of compound $\mathbf{6}$

${ }^{13} \mathrm{C}$ NMR of compound 6

${ }^{1} \mathrm{H}$ NMR of compound 7

S7

${ }^{13} \mathrm{C}$ NMR of compound 7

${ }^{1} \mathrm{H}$ NMR of compound 8

${ }^{13} \mathrm{C}$ NMR of compound 8

$\mathrm{S} 10$

${ }^{1} \mathrm{H}$ NMR of compound $\mathbf{1 0}$

S11

${ }^{13} \mathrm{C}$ NMR of compound $\mathbf{1 0}$

S12

${ }^{1} \mathrm{H}$ NMR of compound $\mathbf{1 1}$

$\mathrm{S} 13$

${ }^{13} \mathrm{C}$ NMR of compound $\mathbf{1 1}$

S14

${ }^{1} \mathrm{H}$ NMR of compound $\mathbf{1 5}$

$\mathrm{S} 15$

${ }^{13} \mathrm{C}$ NMR of compound $\mathbf{1 5}$

$\mathrm{S} 16$

${ }^{1} \mathrm{H}$ NMR of compound $\mathbf{1 6}$

S17

${ }^{1} \mathrm{H}$ NMR of compound $\mathbf{1 8}$

$\mathrm{S} 18$

${ }^{1} \mathrm{H}$ NMR of compound 19

S19

${ }^{13} \mathrm{C}$ NMR of compound 19

S20

${ }^{1} \mathrm{H}$ NMR of compound $\mathbf{2 0}$

$\mathrm{S} 21$

${ }^{13} \mathrm{C}$ NMR of compound $\mathbf{2 0}$

$\mathrm{S} 22$

${ }^{1} \mathrm{H}$ NMR of compound $\mathbf{2 1}$

S23

${ }^{13} \mathrm{C}$ NMR of compound $\mathbf{2 1}$

S24

${ }^{1} \mathrm{H}$ NMR of compound 22

${ }^{13} \mathrm{C}$ NMR of compound 22

S25

${ }^{1} \mathrm{H}$ NMR of compound $23 \beta$

$\mathrm{S} 26$

${ }^{13} \mathrm{C}$ NMR of compound $23 \beta$

$\mathrm{S} 27$

${ }^{1} \mathrm{H}$ NMR of compound $\mathbf{2 6} \alpha$

${ }^{13} \mathrm{C}$ NMR of compound $\mathbf{2 6} \alpha$

S29

${ }^{1} \mathrm{H}$ NMR of compound $26 \beta$ 
${ }^{13} \mathrm{C}$ NMR of compound $\mathbf{2 6} \boldsymbol{\beta} \quad \mathrm{S} 32$

${ }^{1} \mathrm{H}$ NMR of compound $\mathbf{2 8} \boldsymbol{\beta} \quad$ S33

${ }^{13} \mathrm{C}$ NMR of compound $\mathbf{2 6} \boldsymbol{\mathrm { N }} \quad \mathrm{S} 34$

$\begin{array}{ll}\text { Computational Section } & \text { S35-S52 }\end{array}$ 


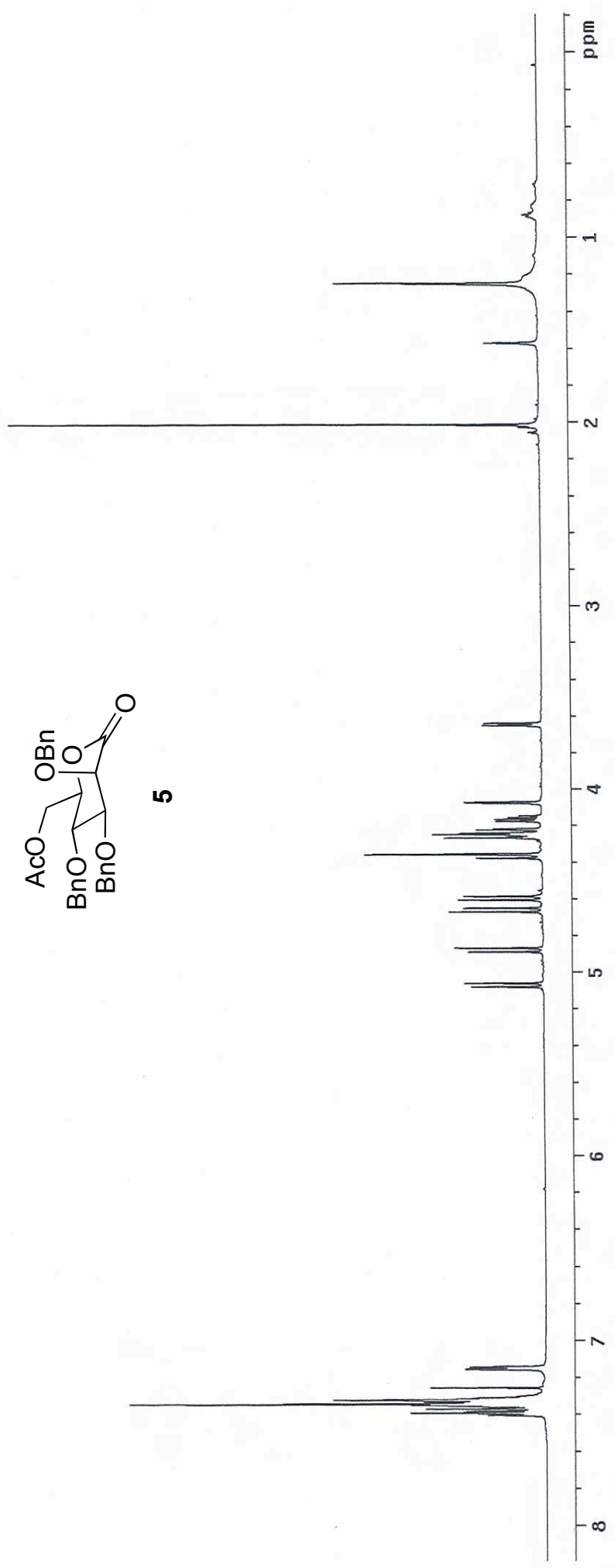




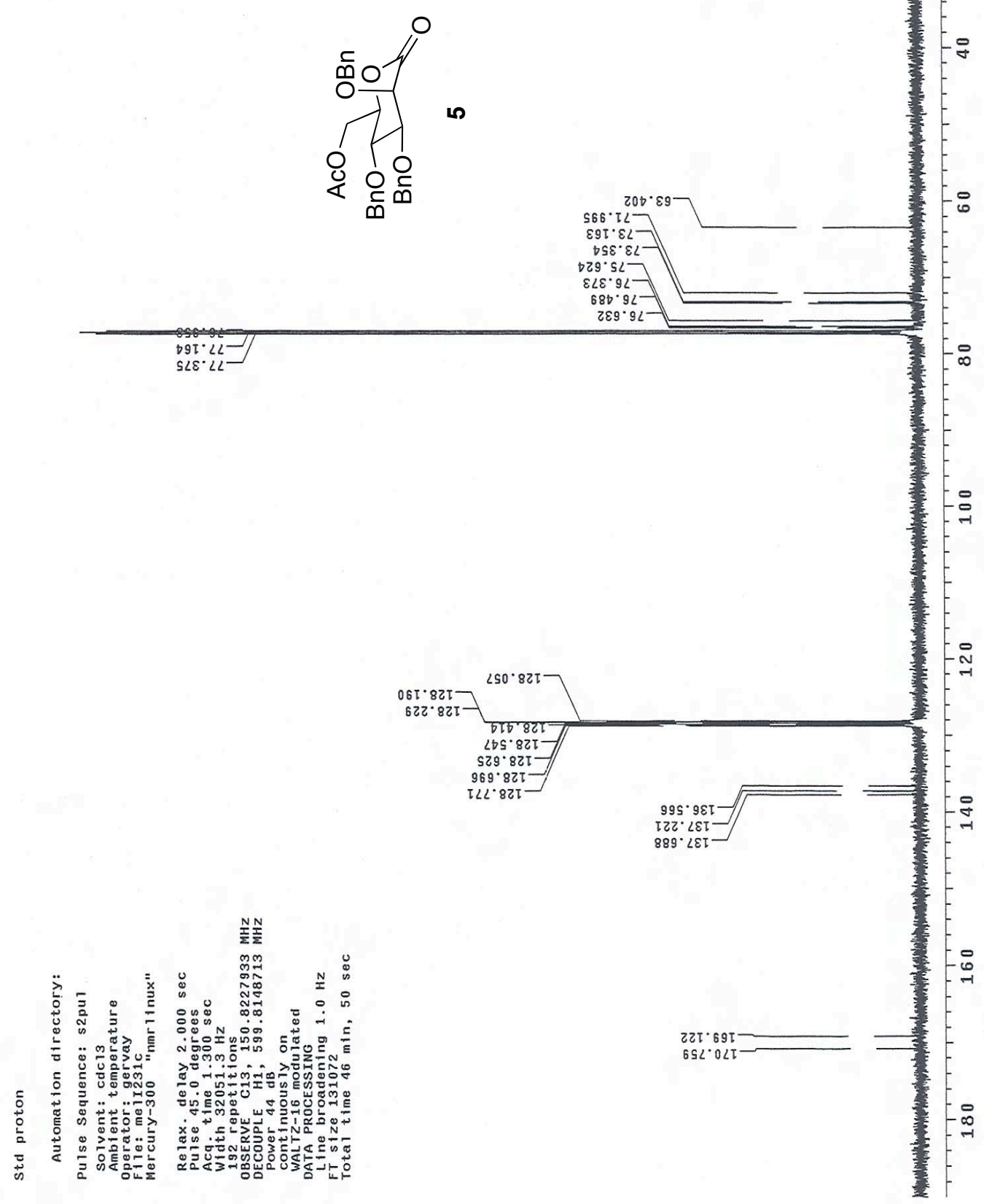




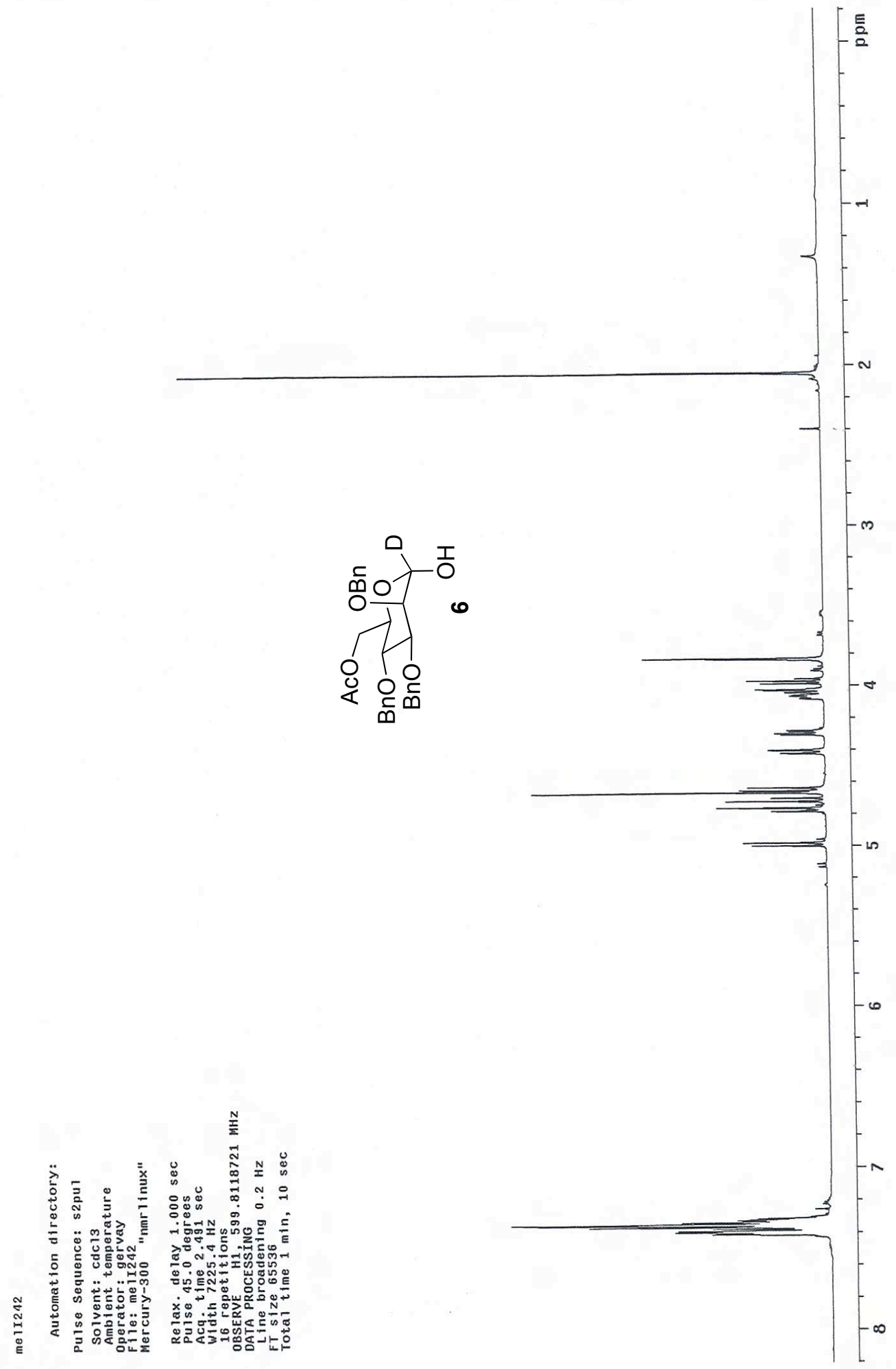




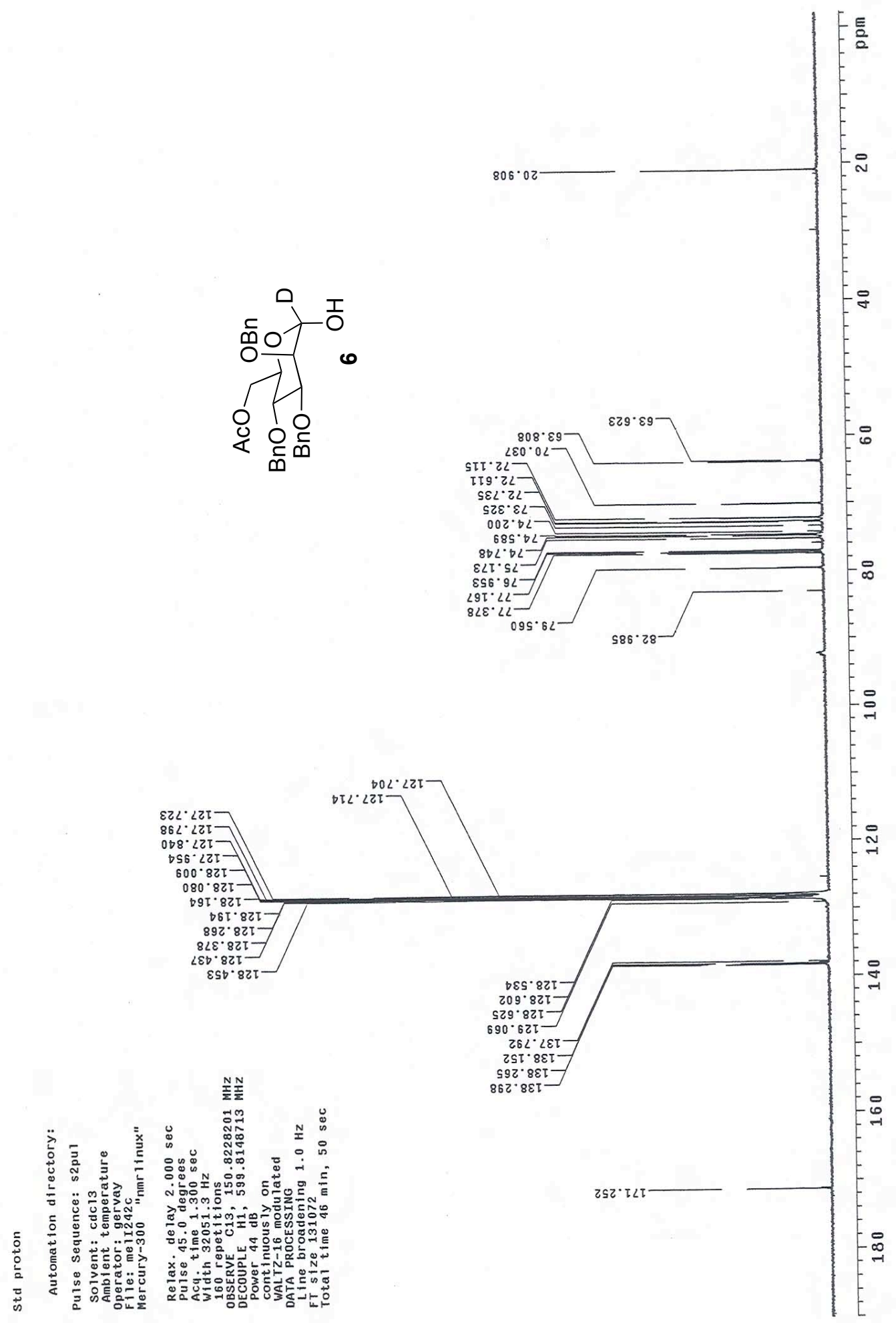



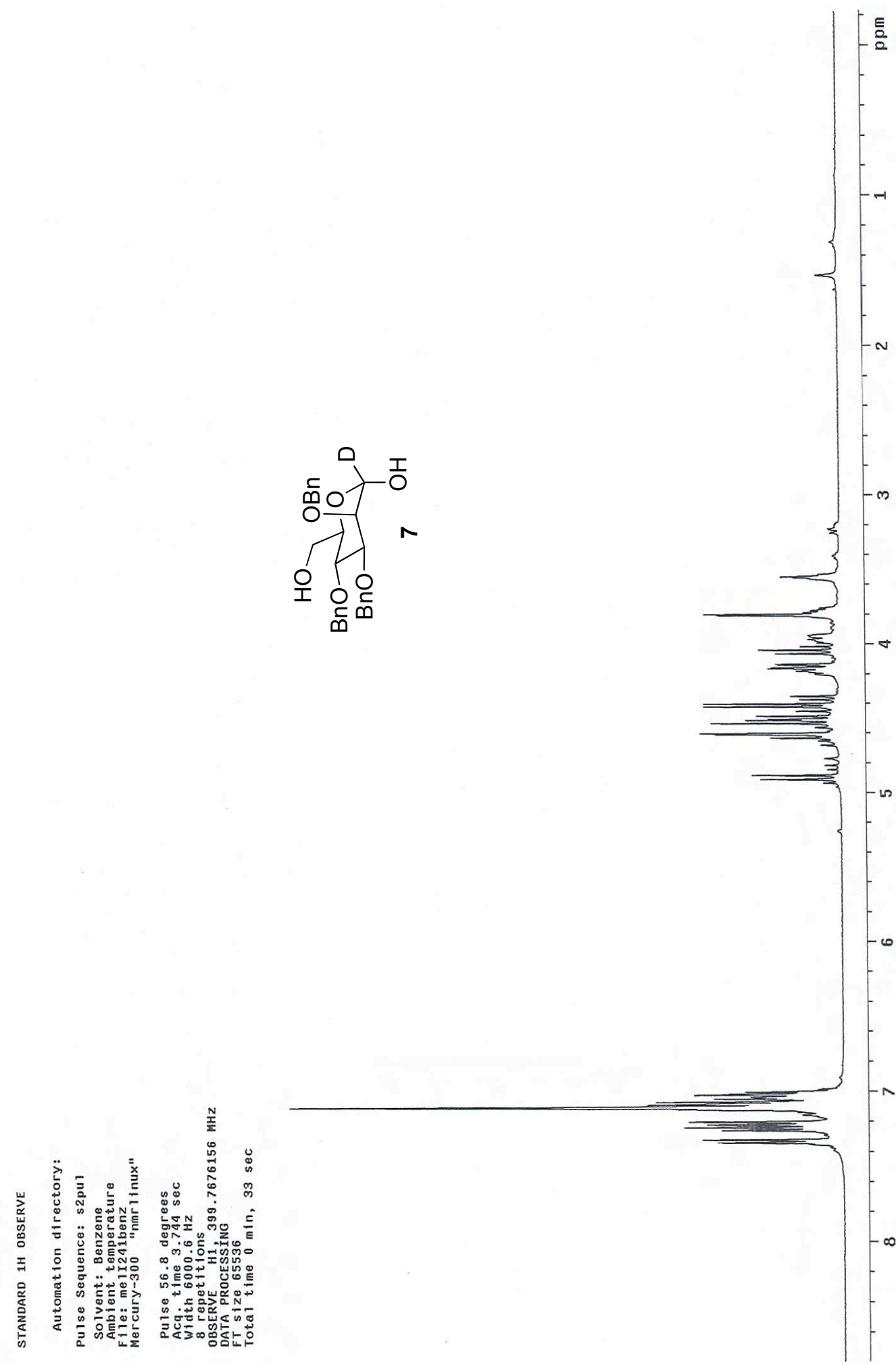


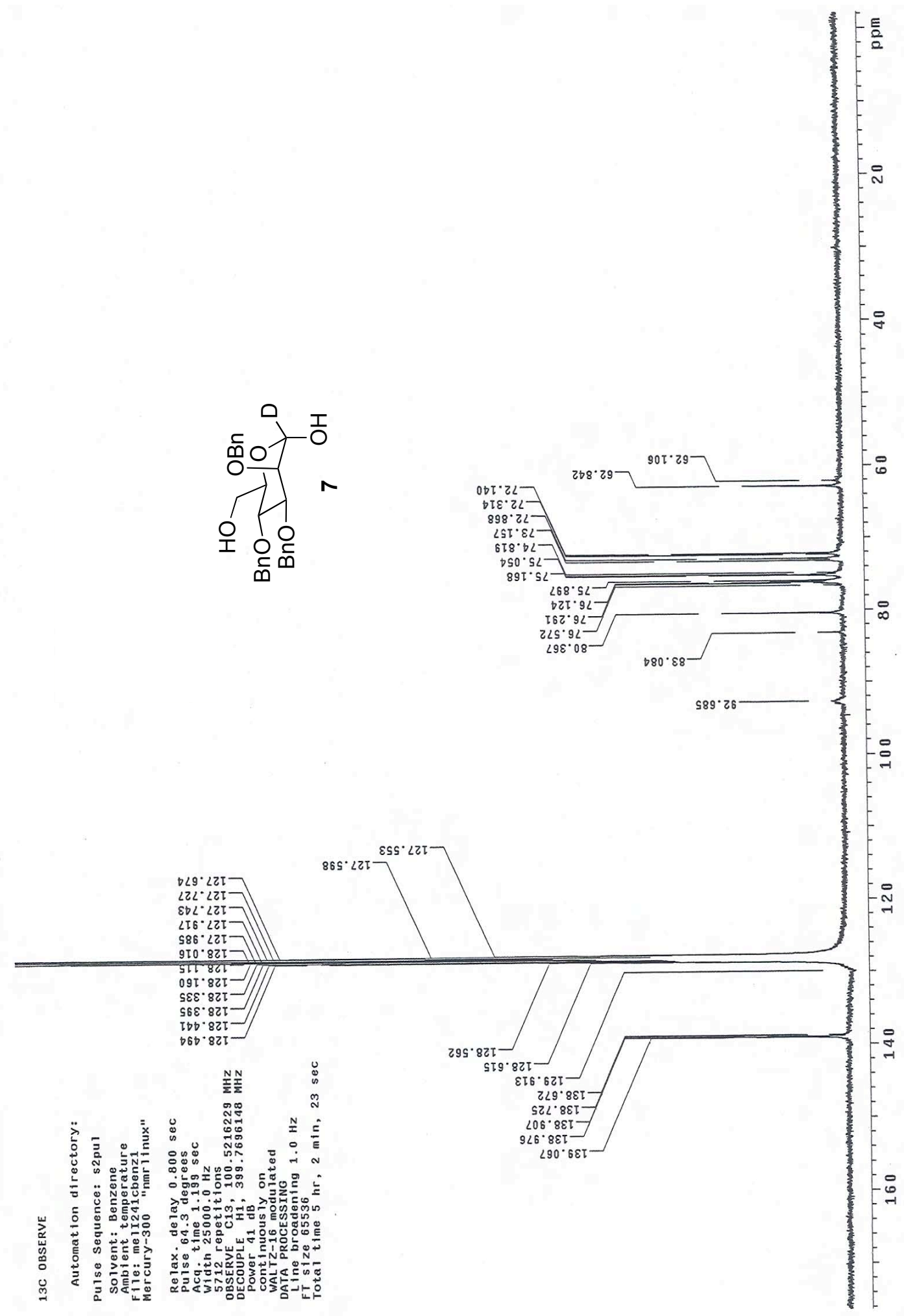




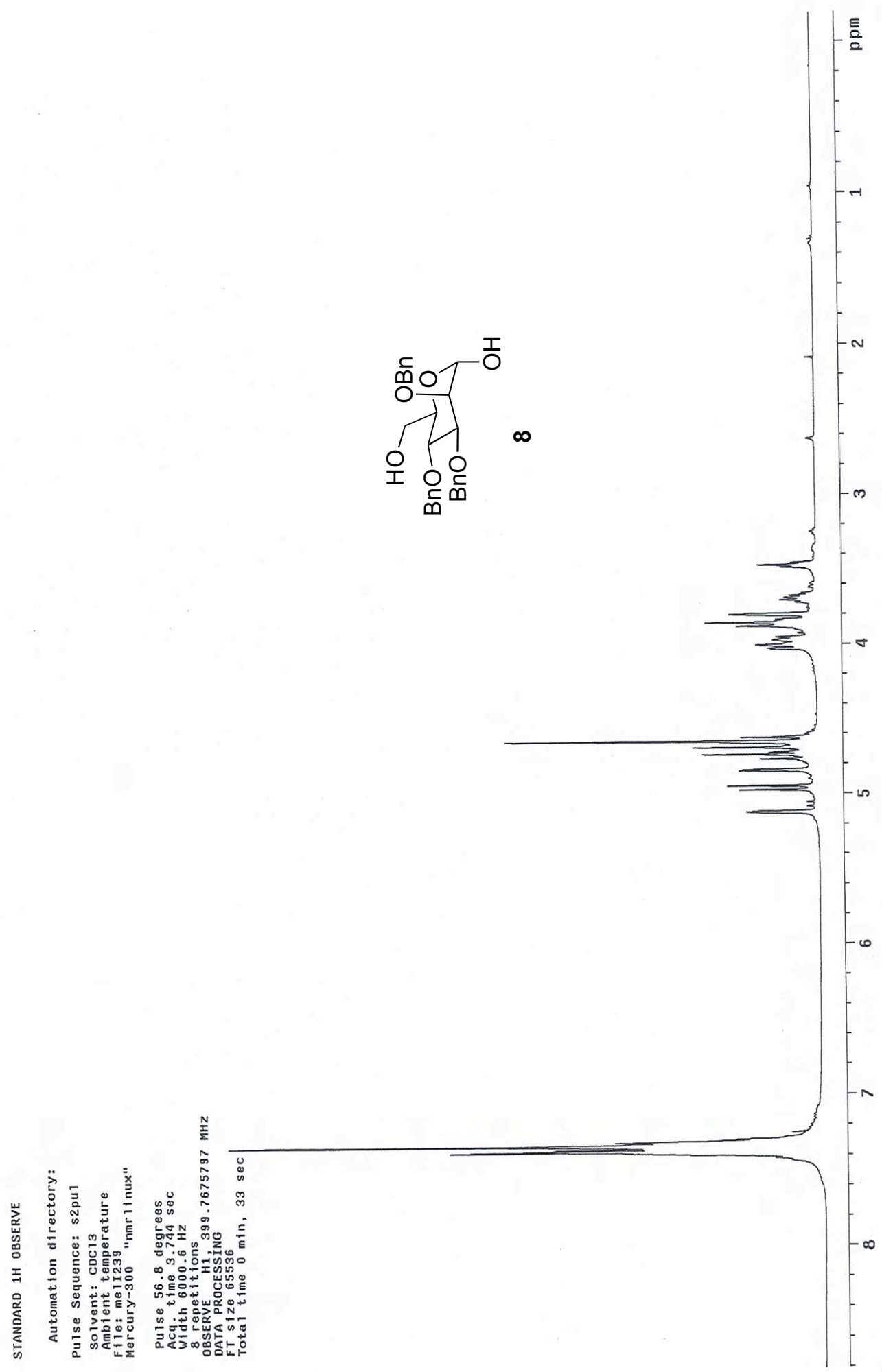




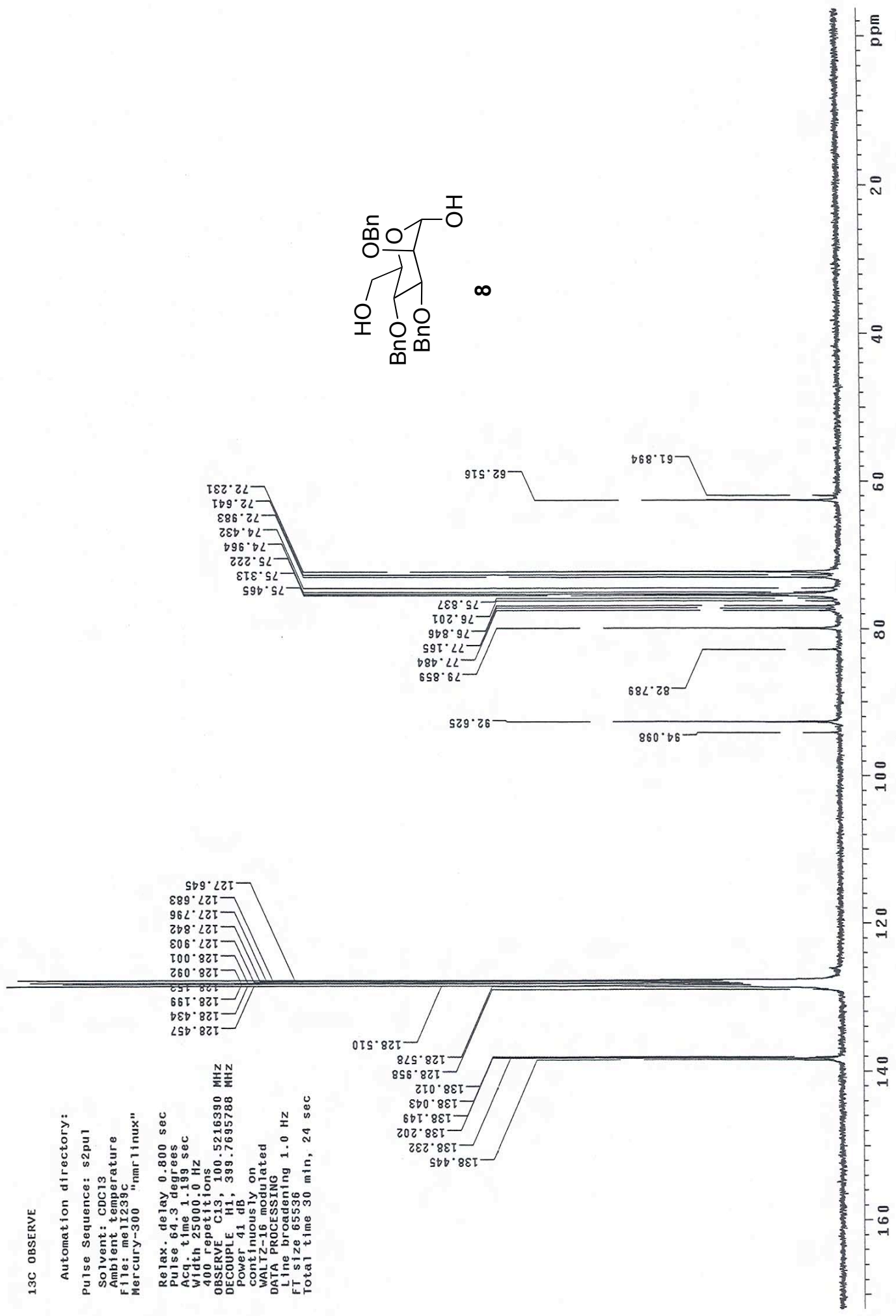




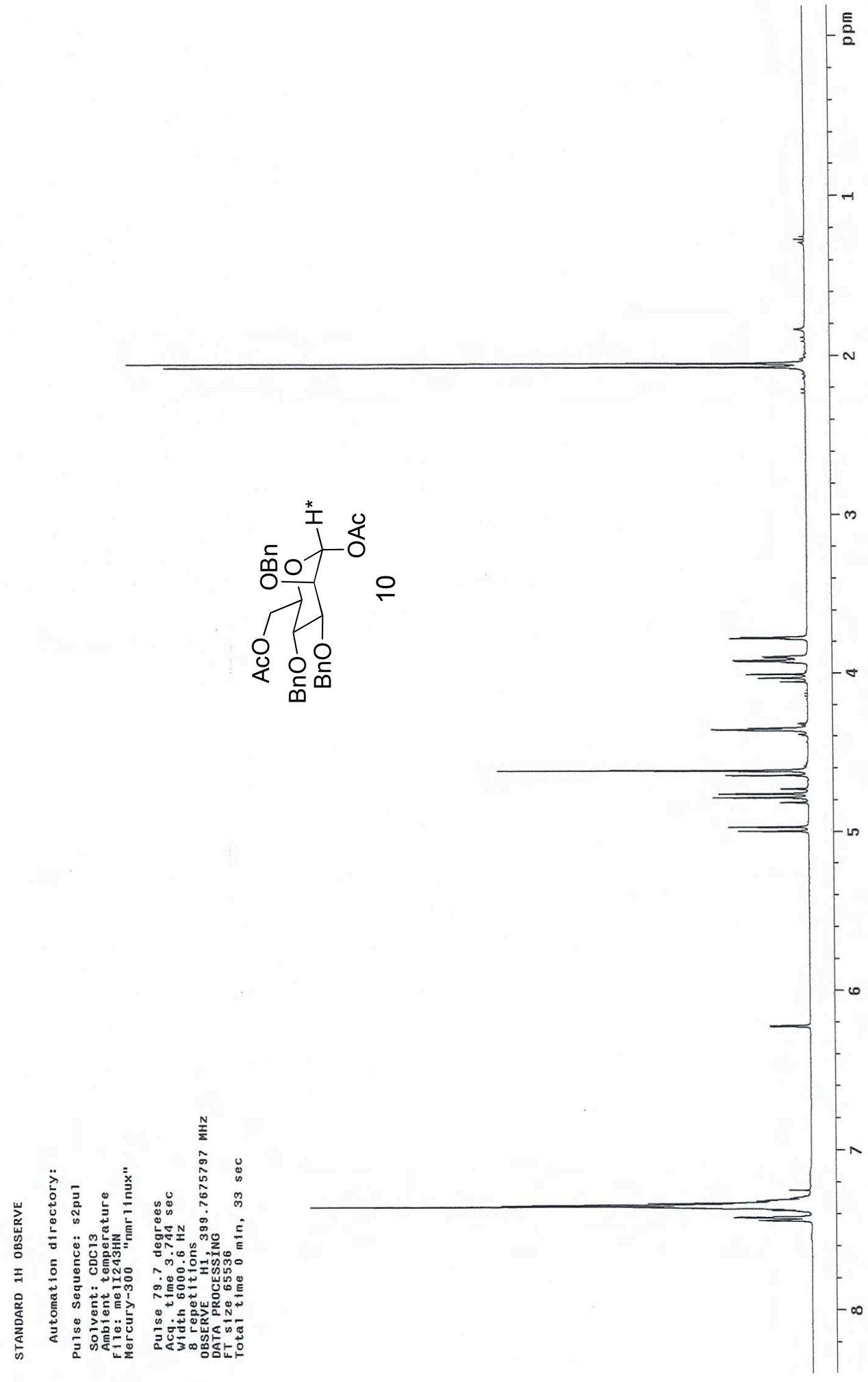




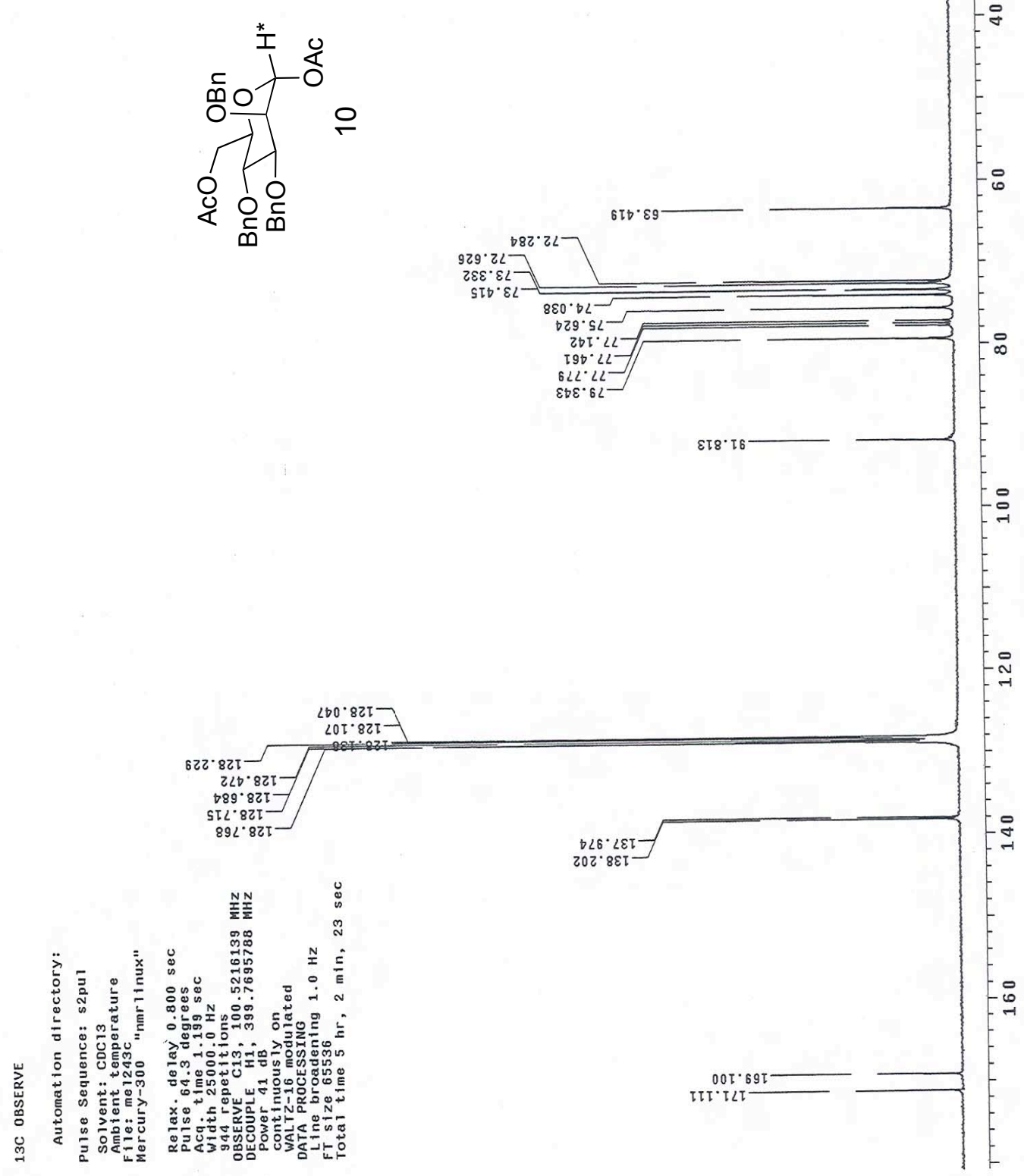




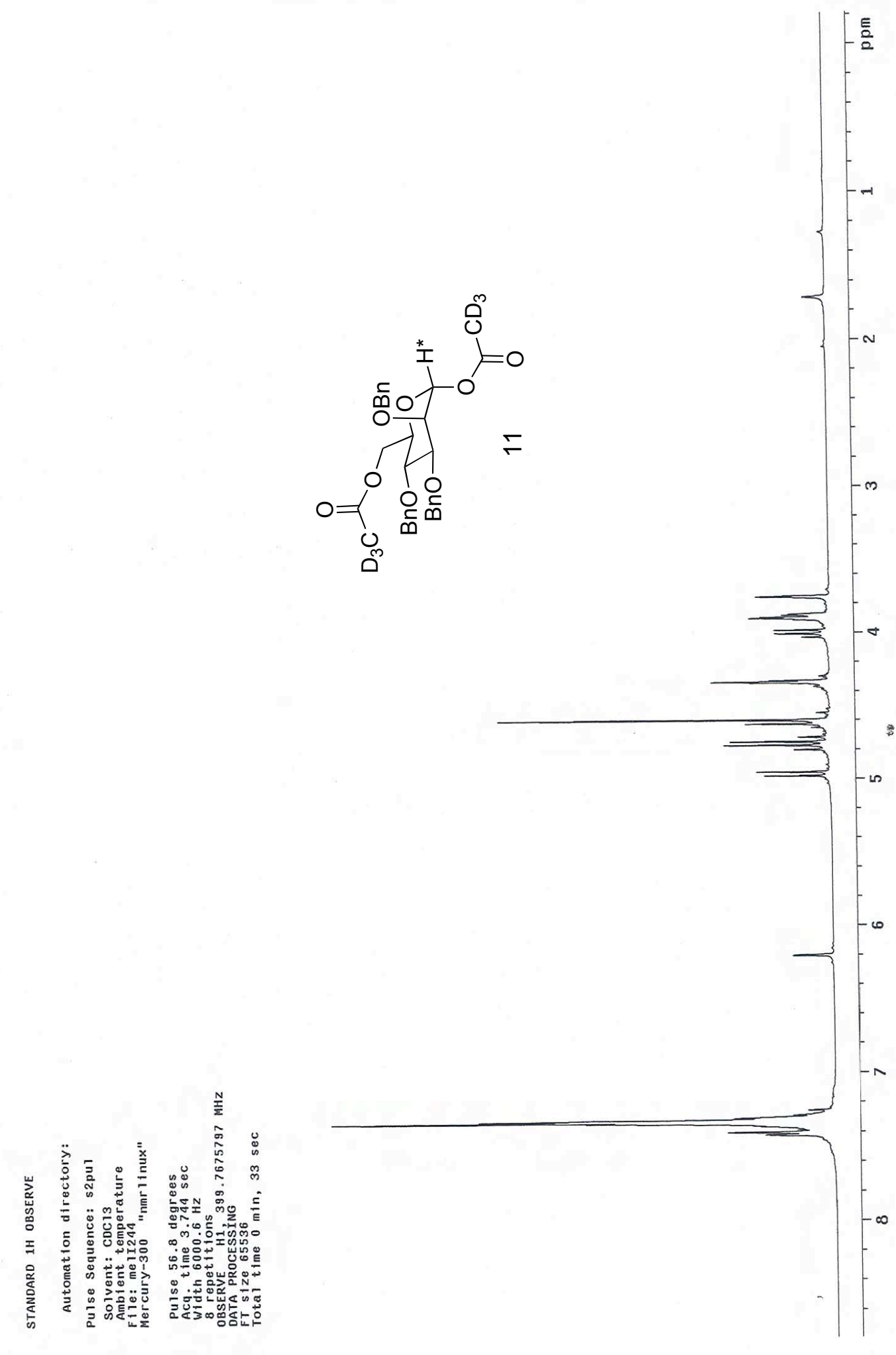




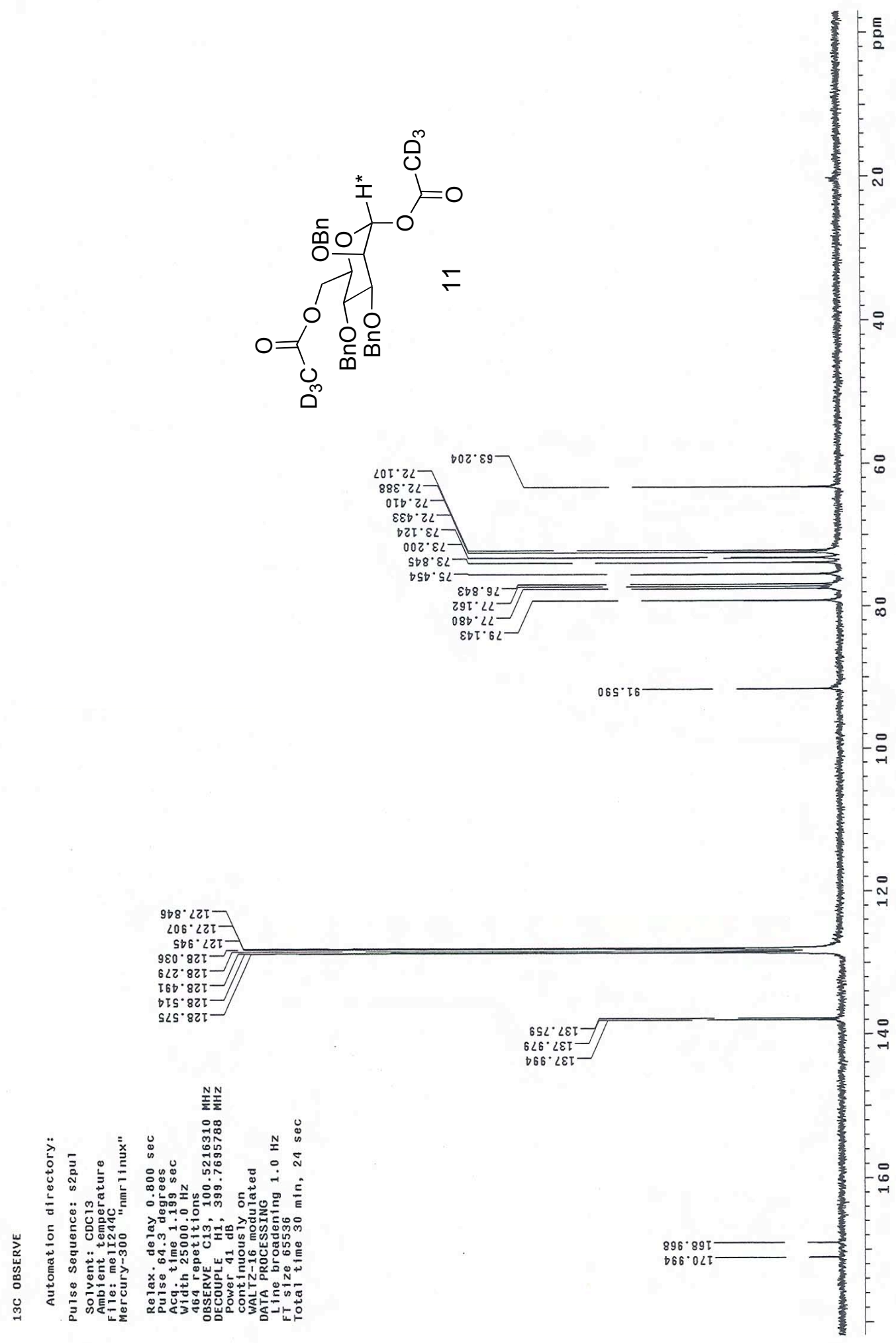




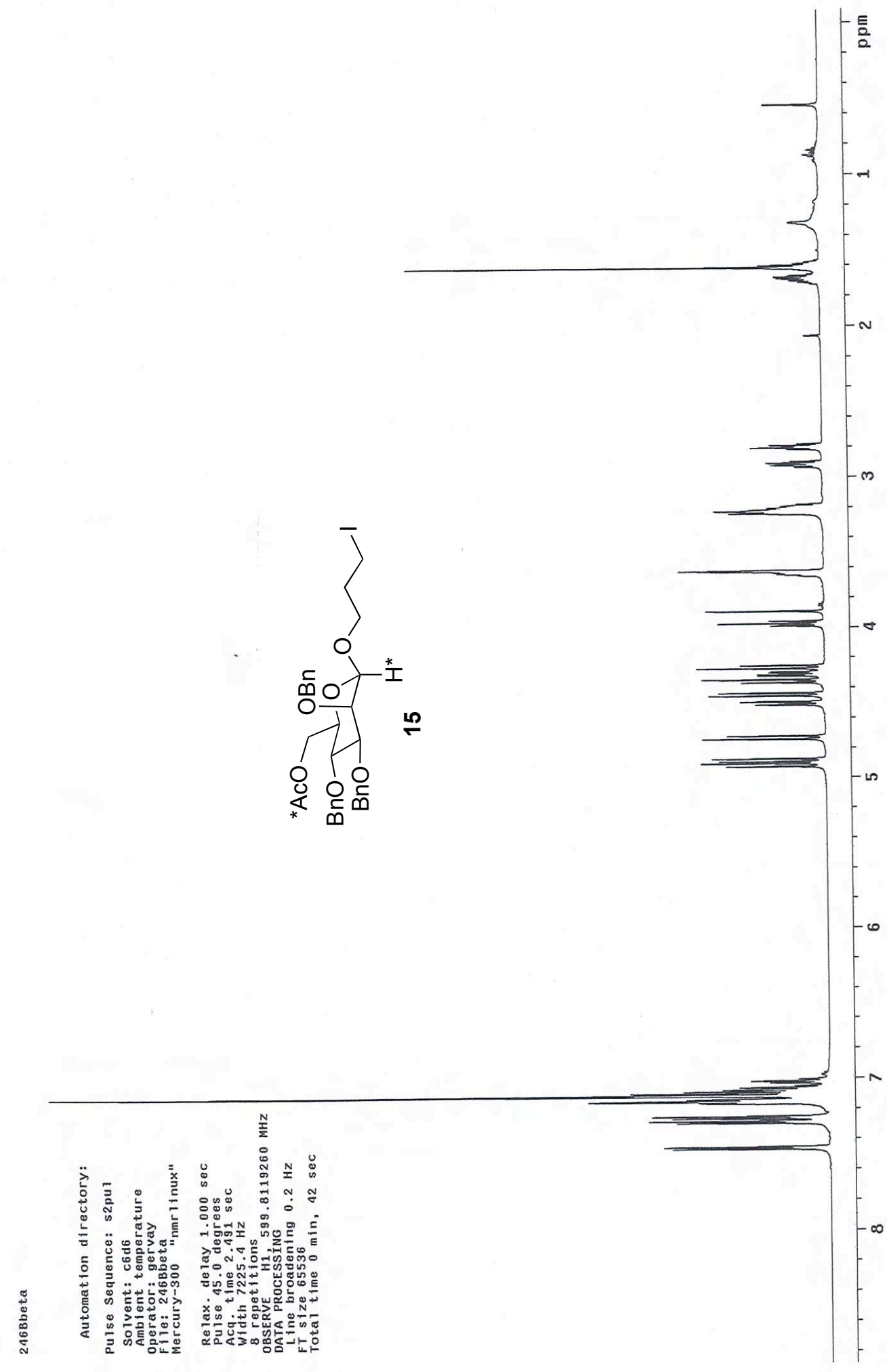



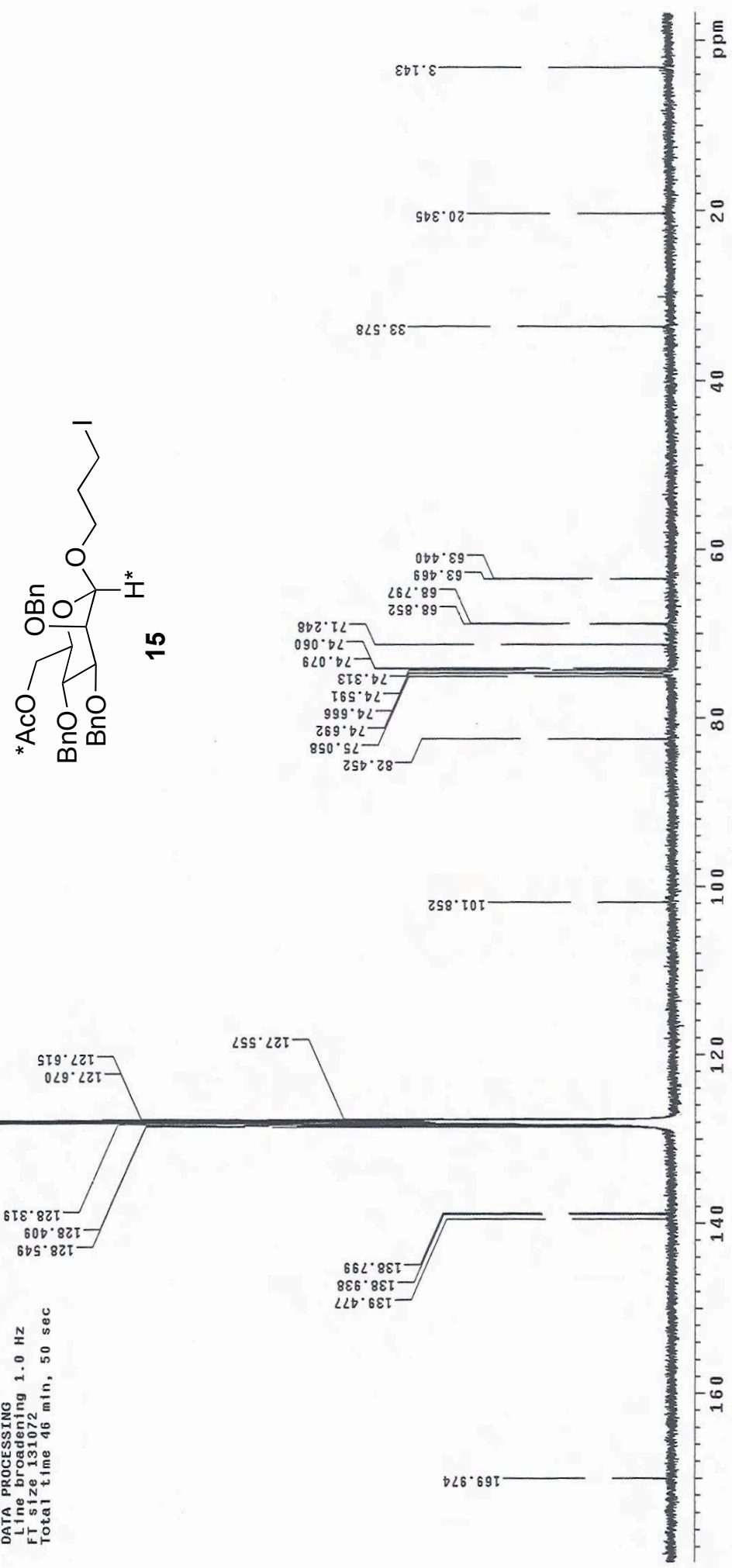

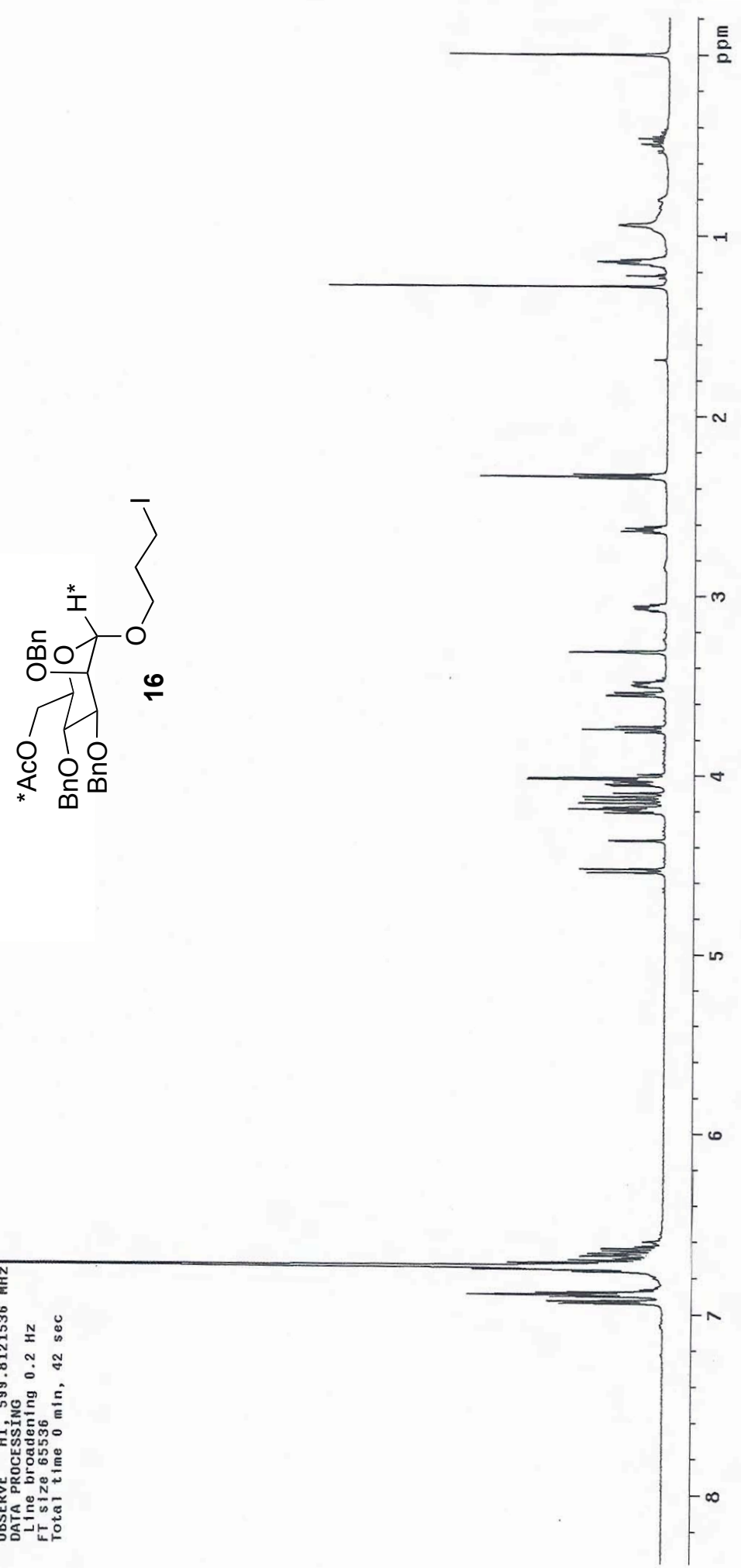


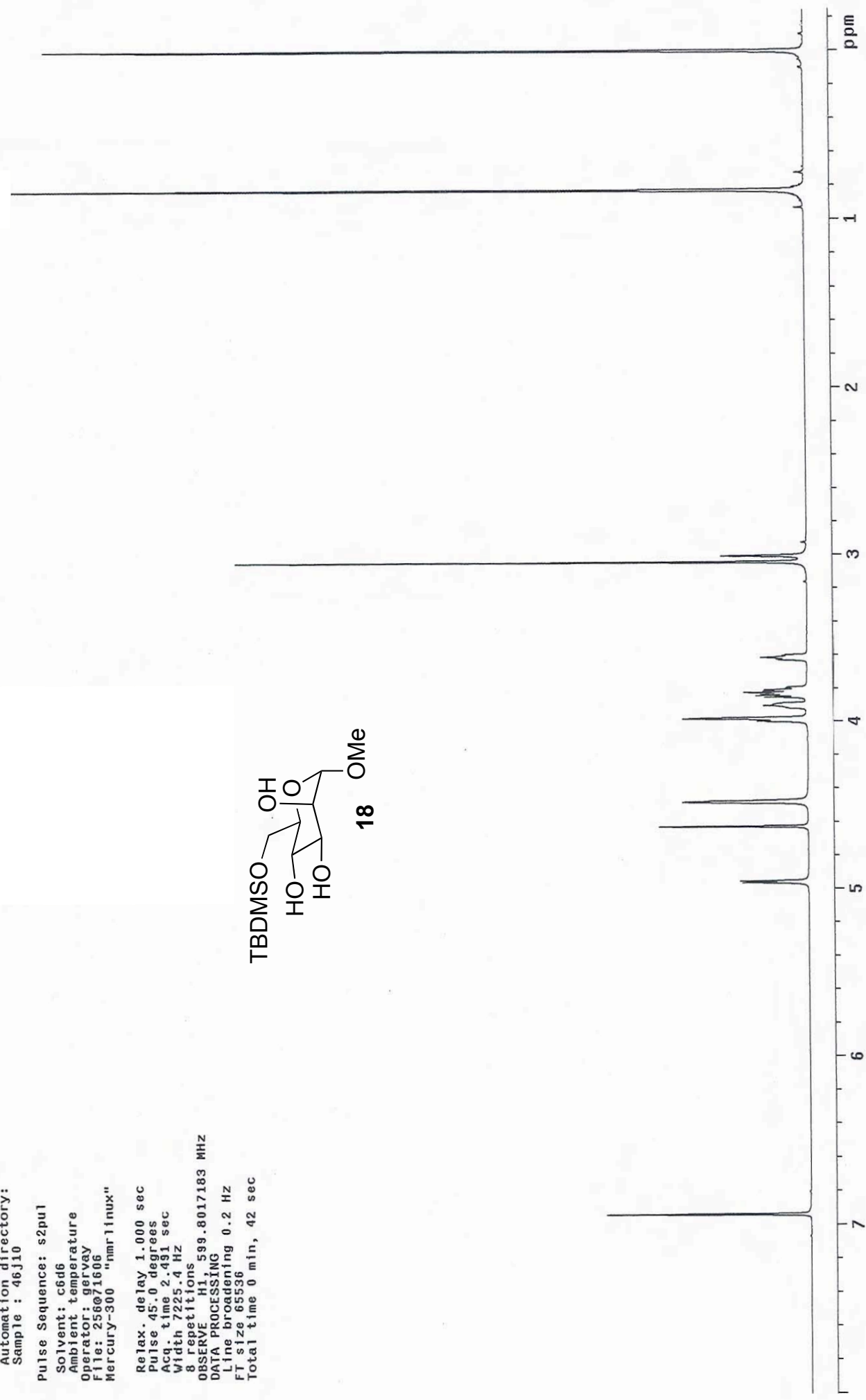




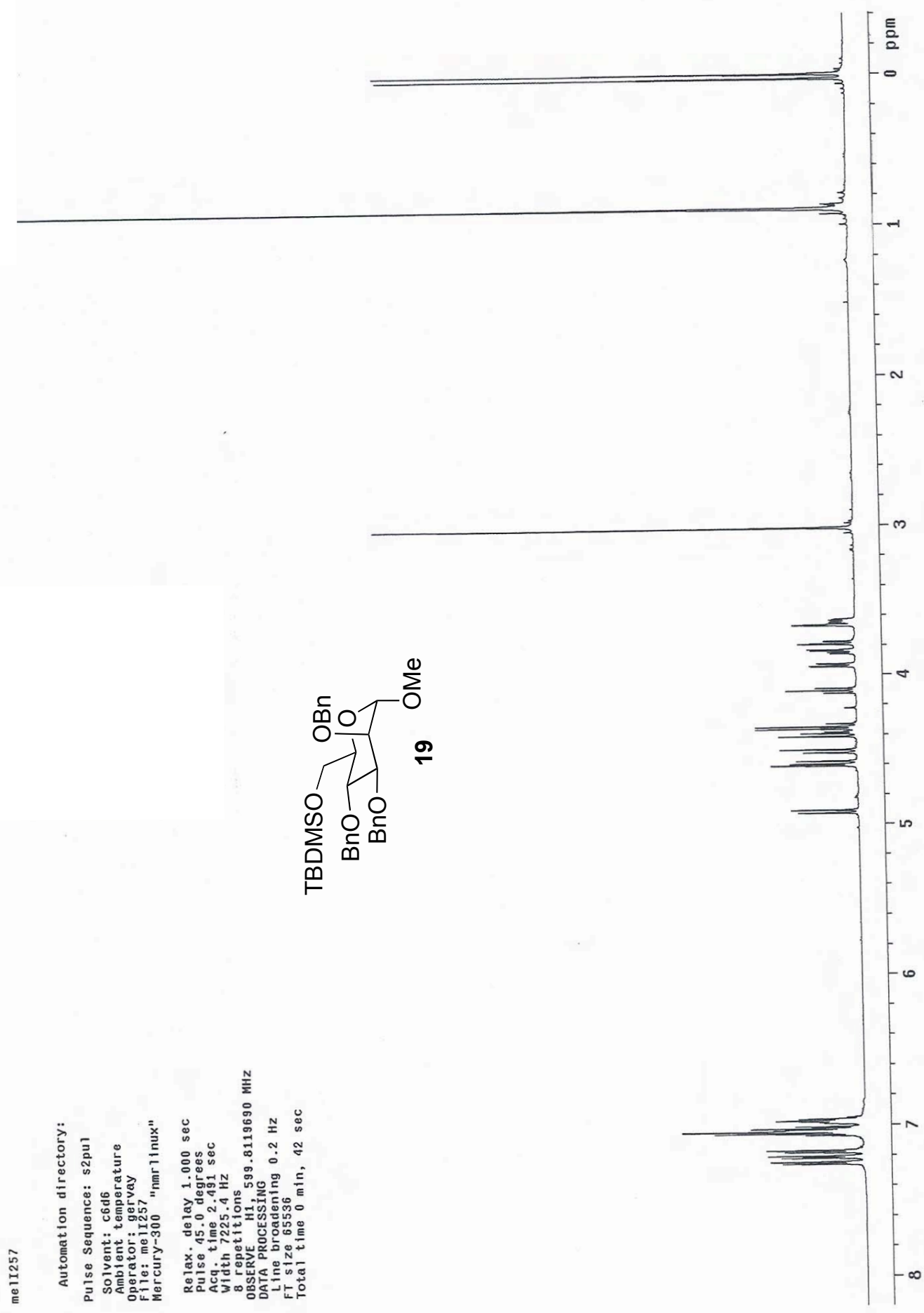



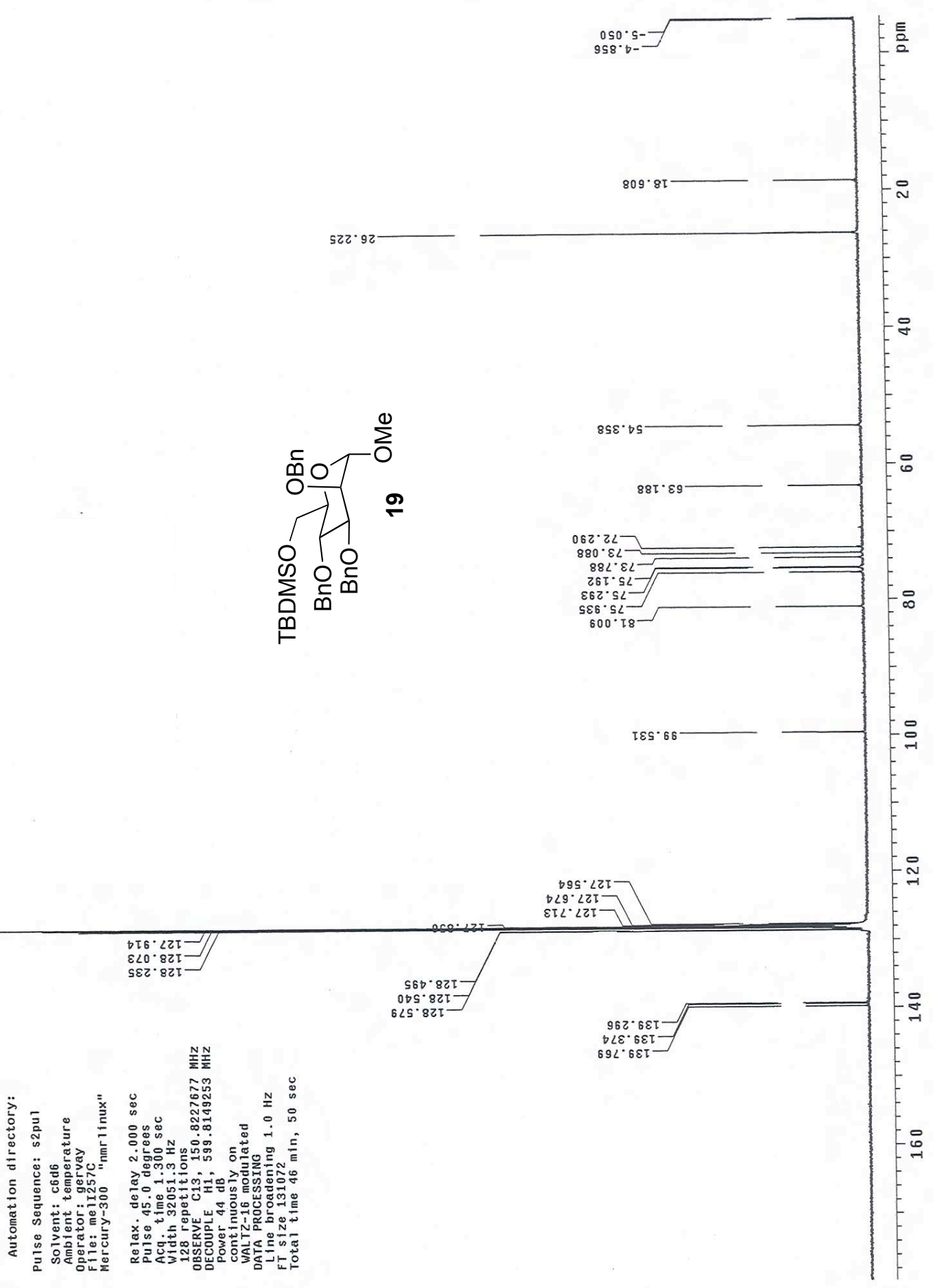


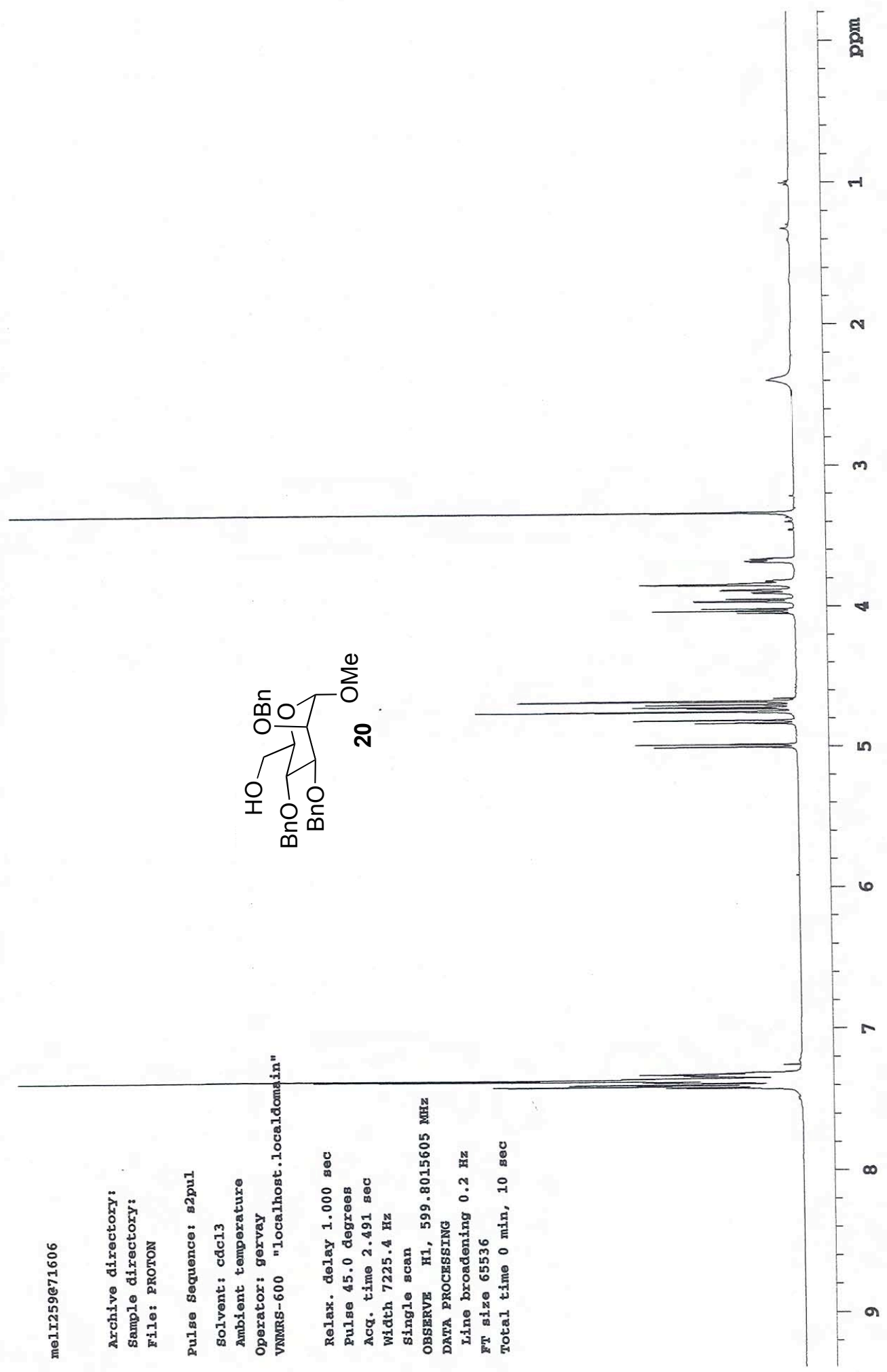




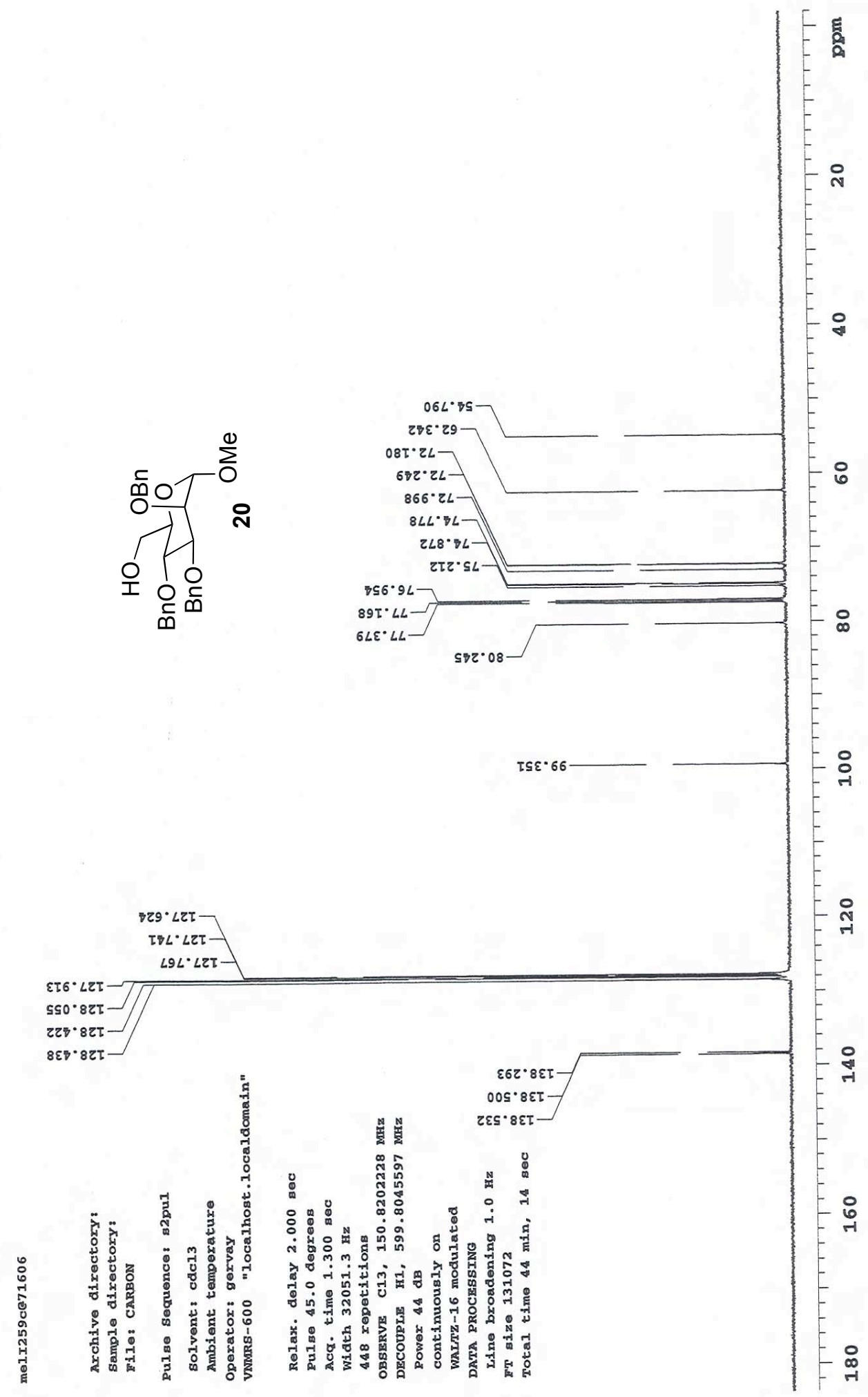




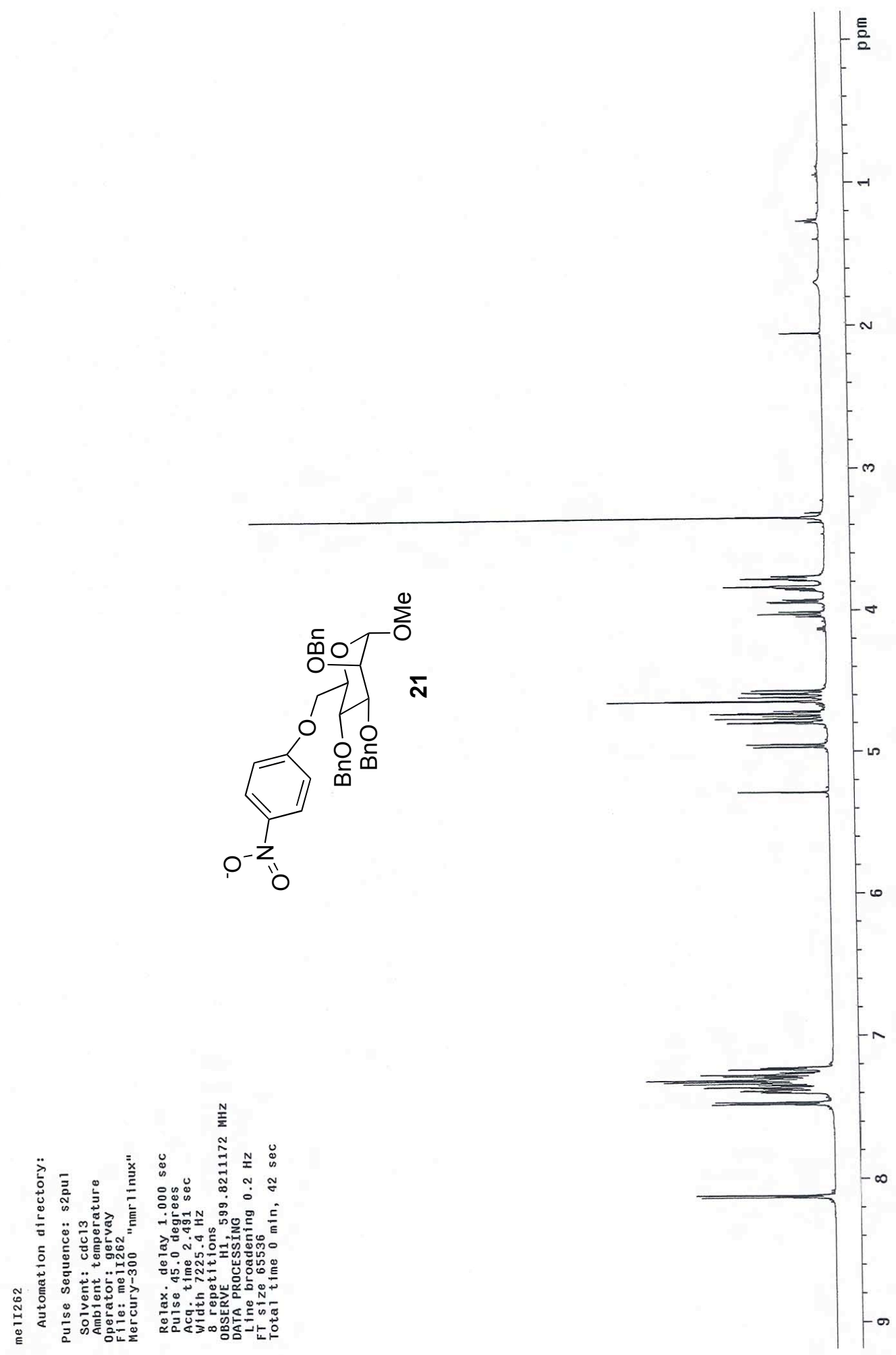




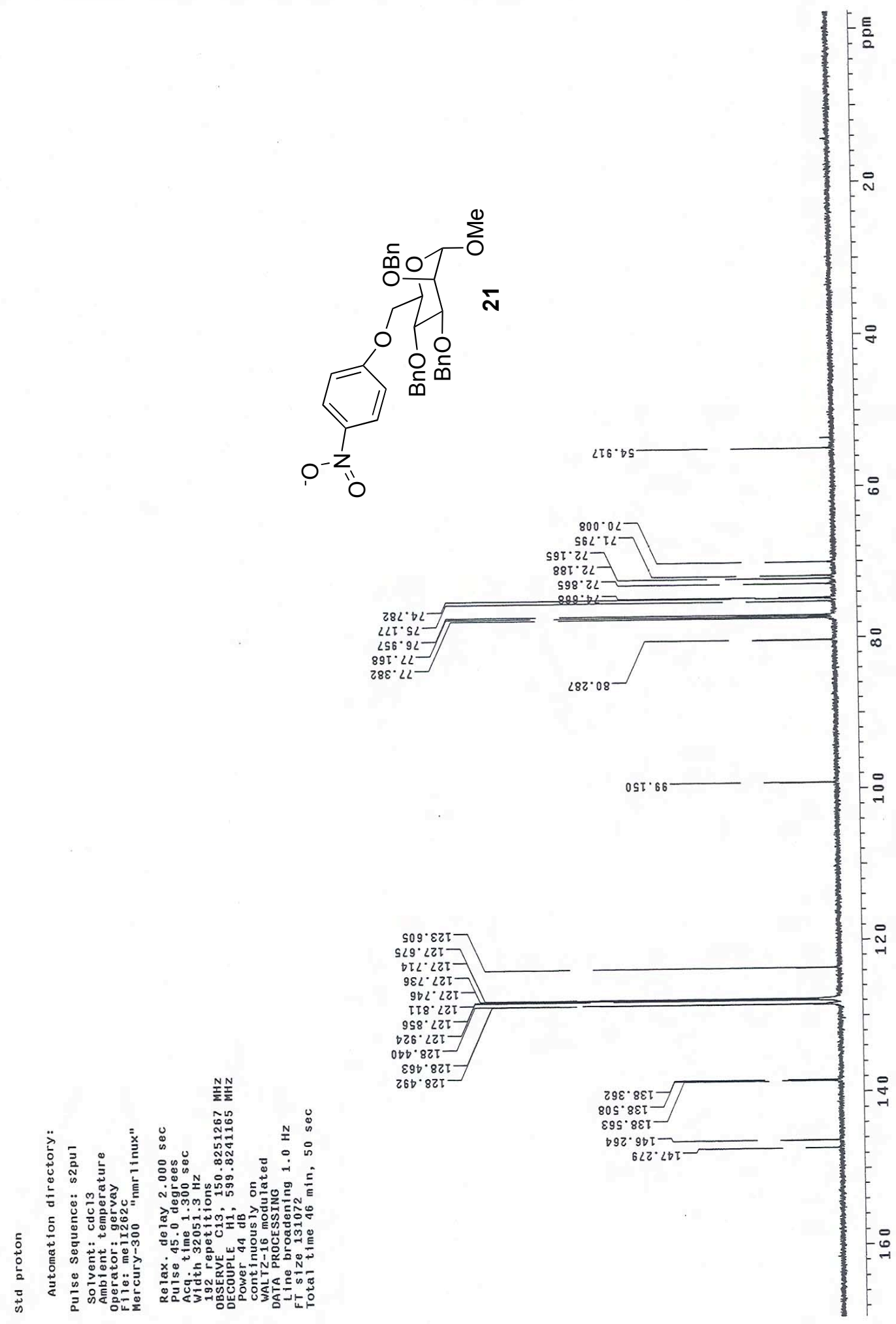




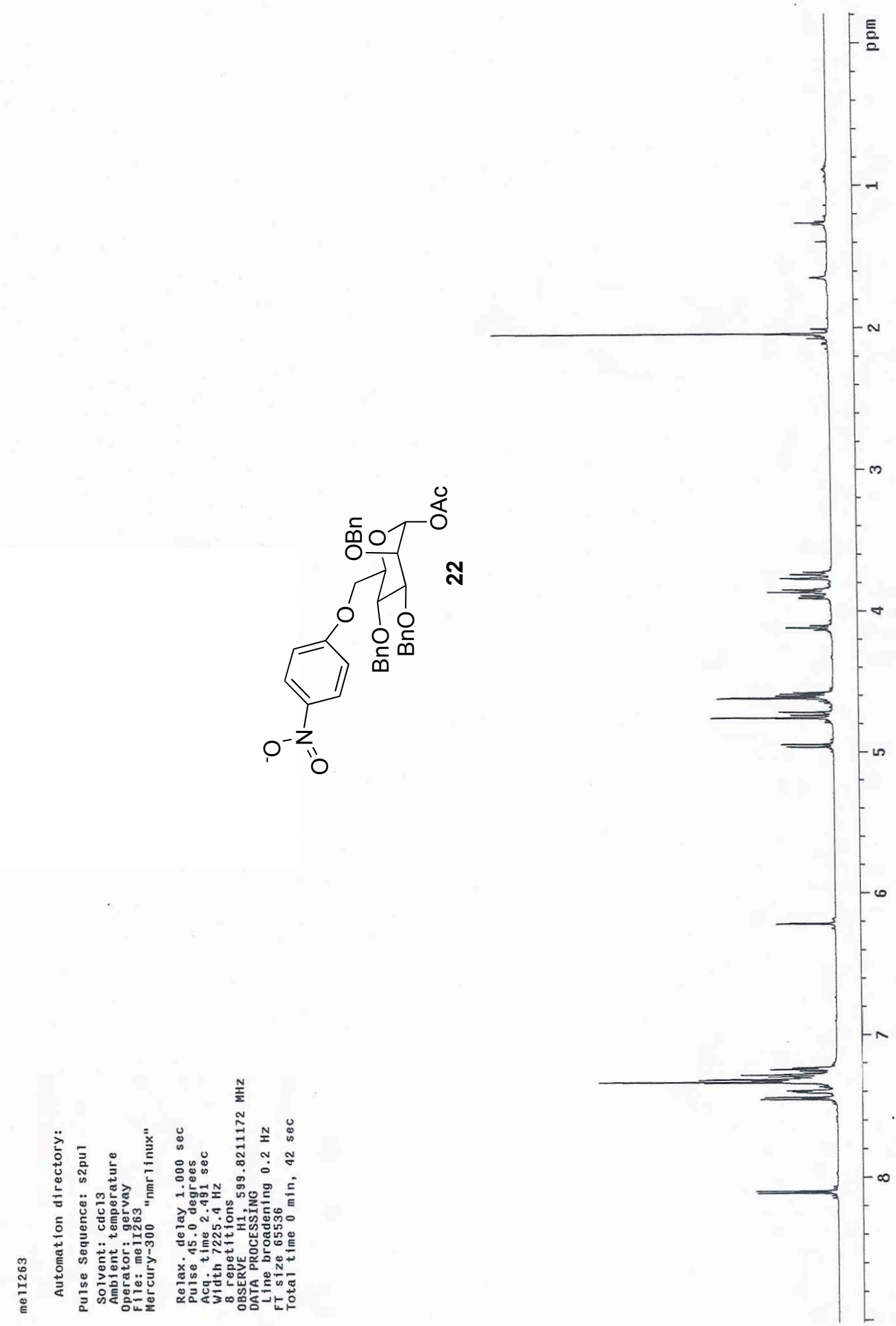




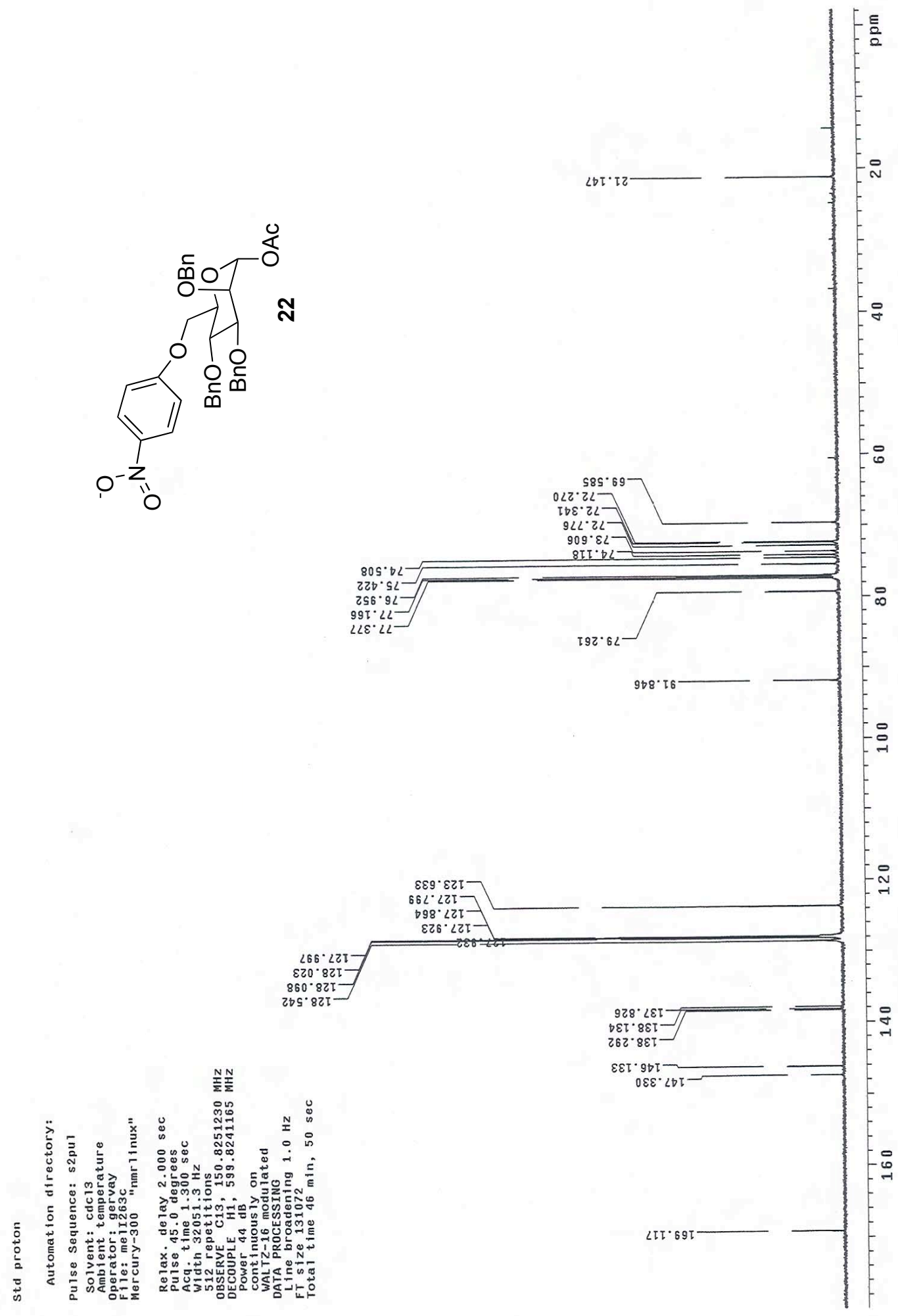




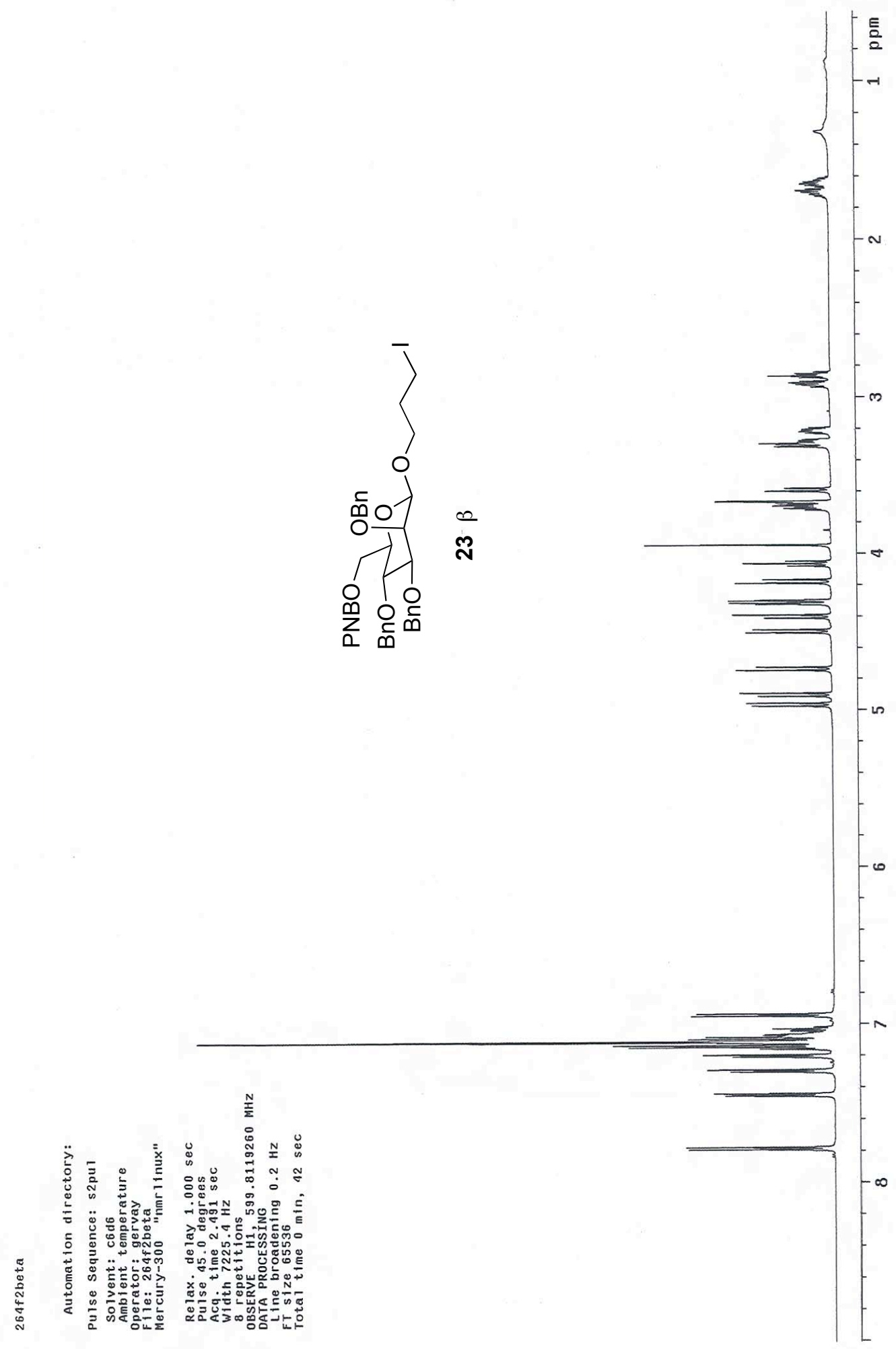




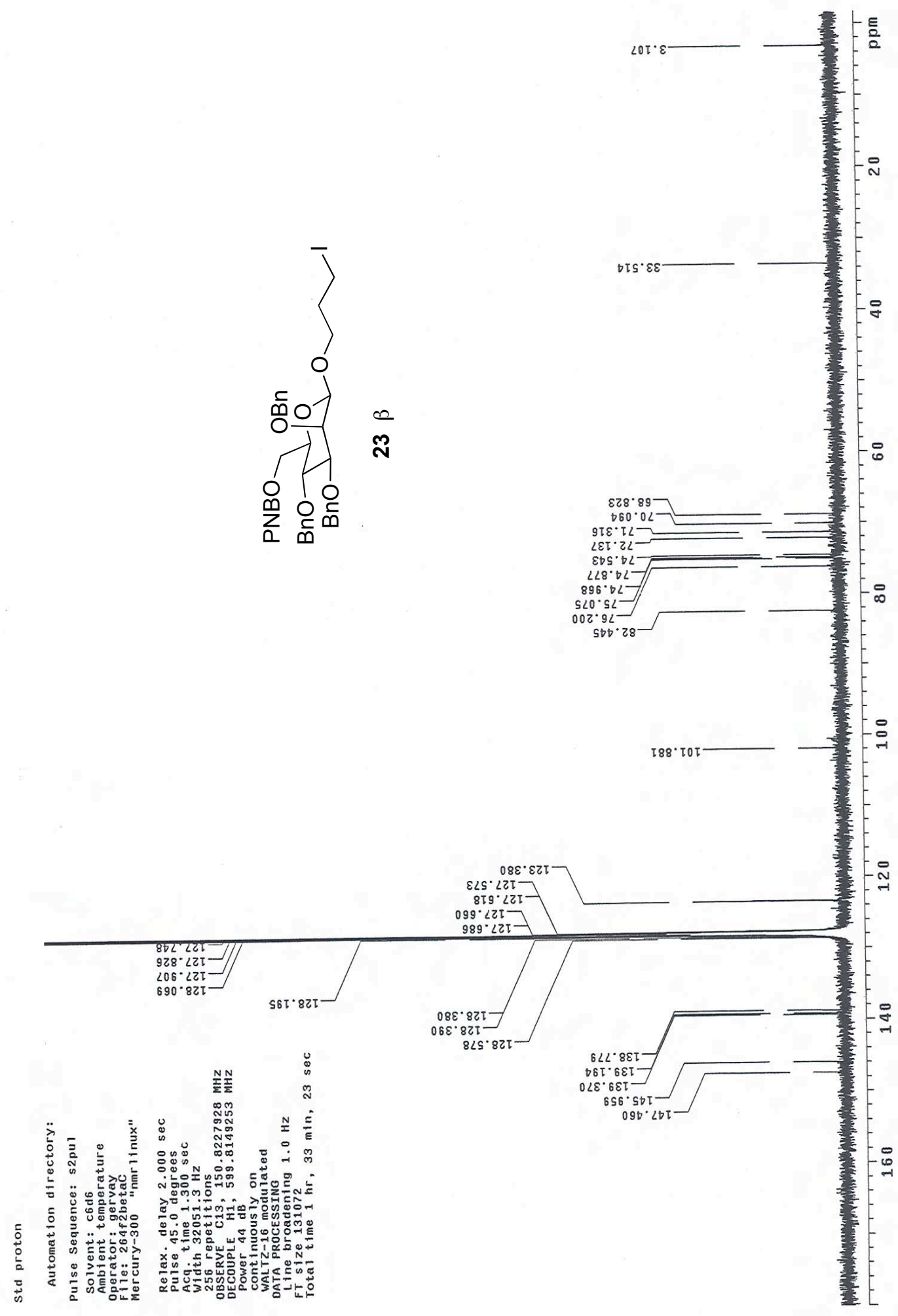




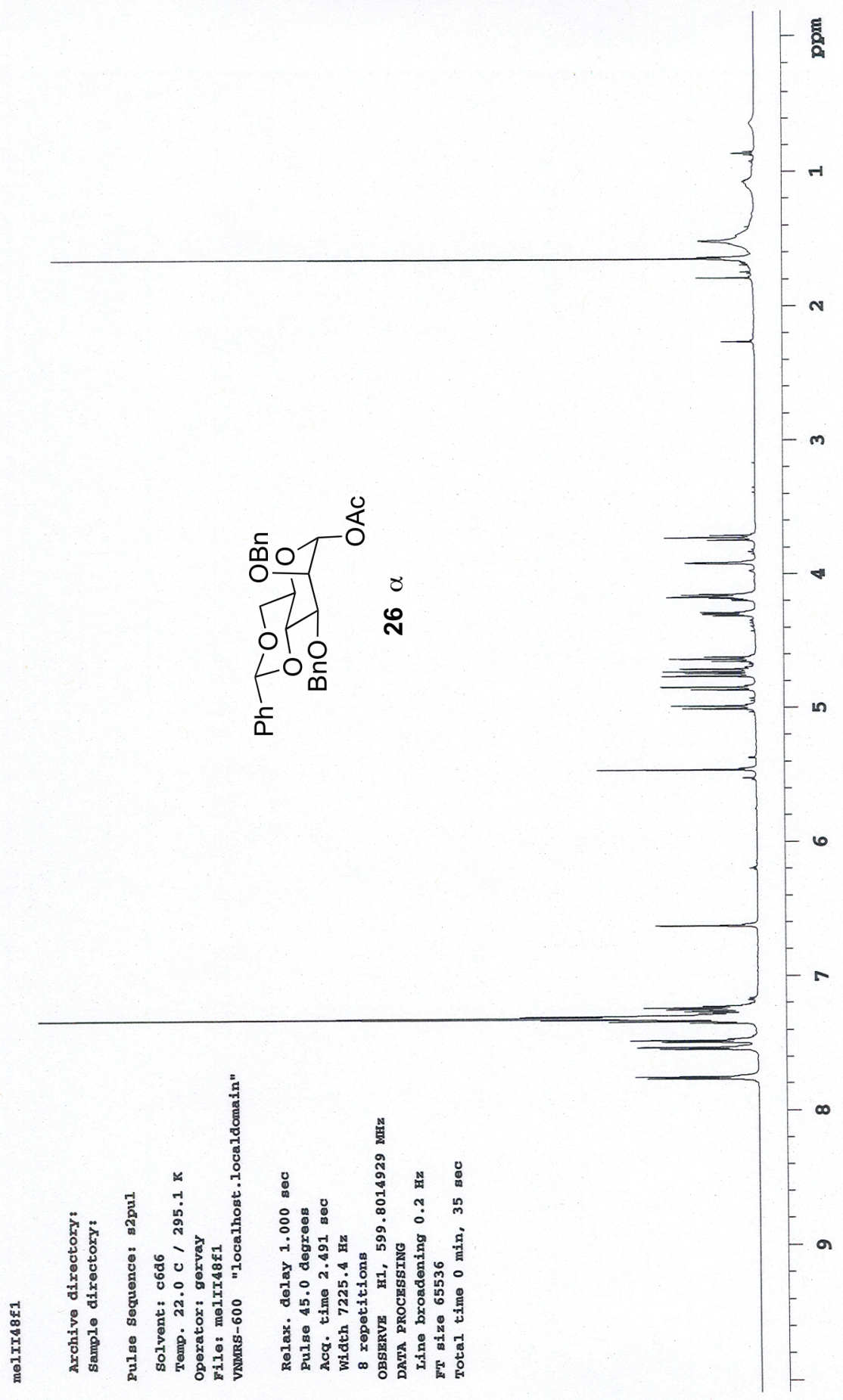




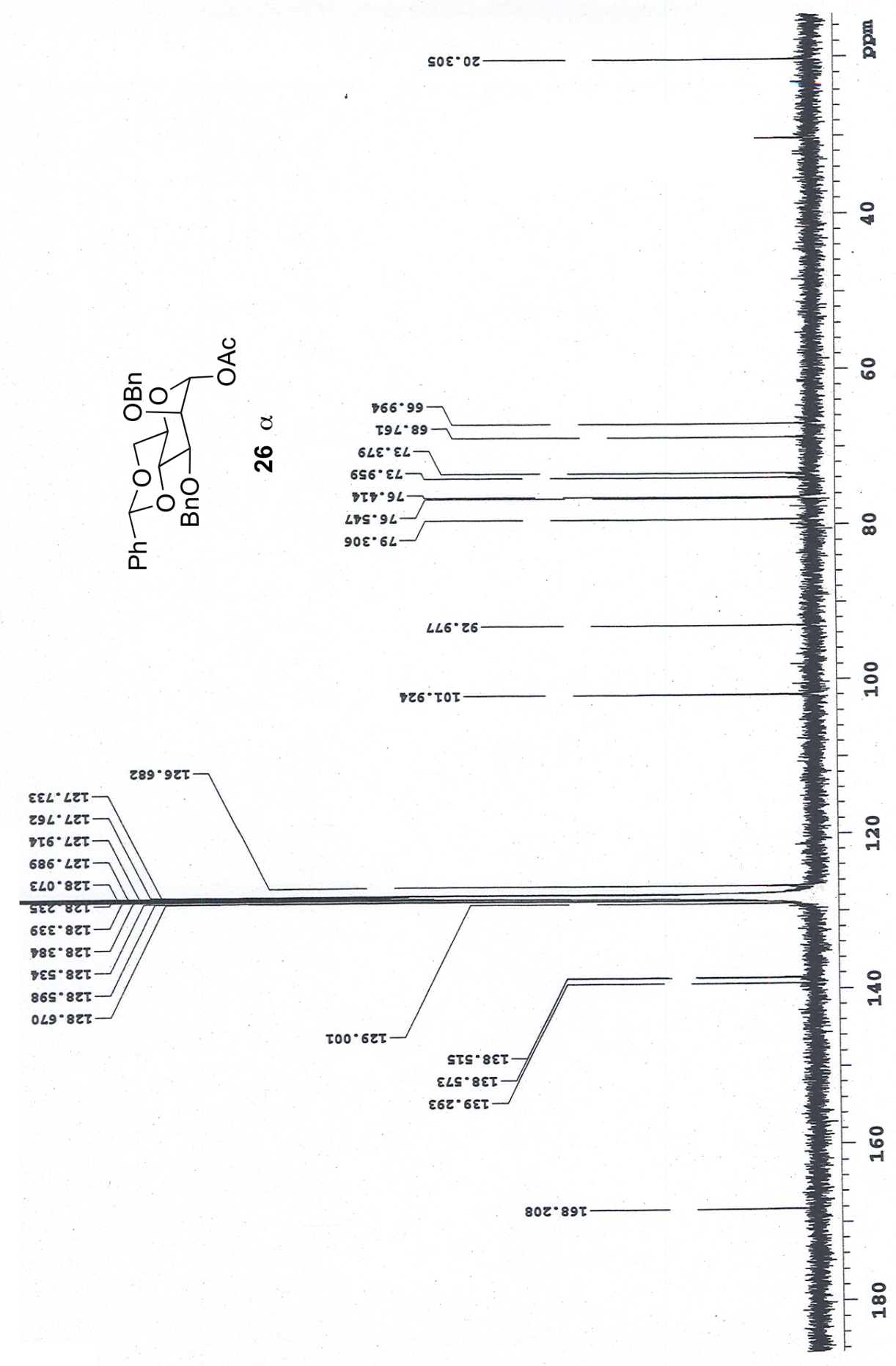




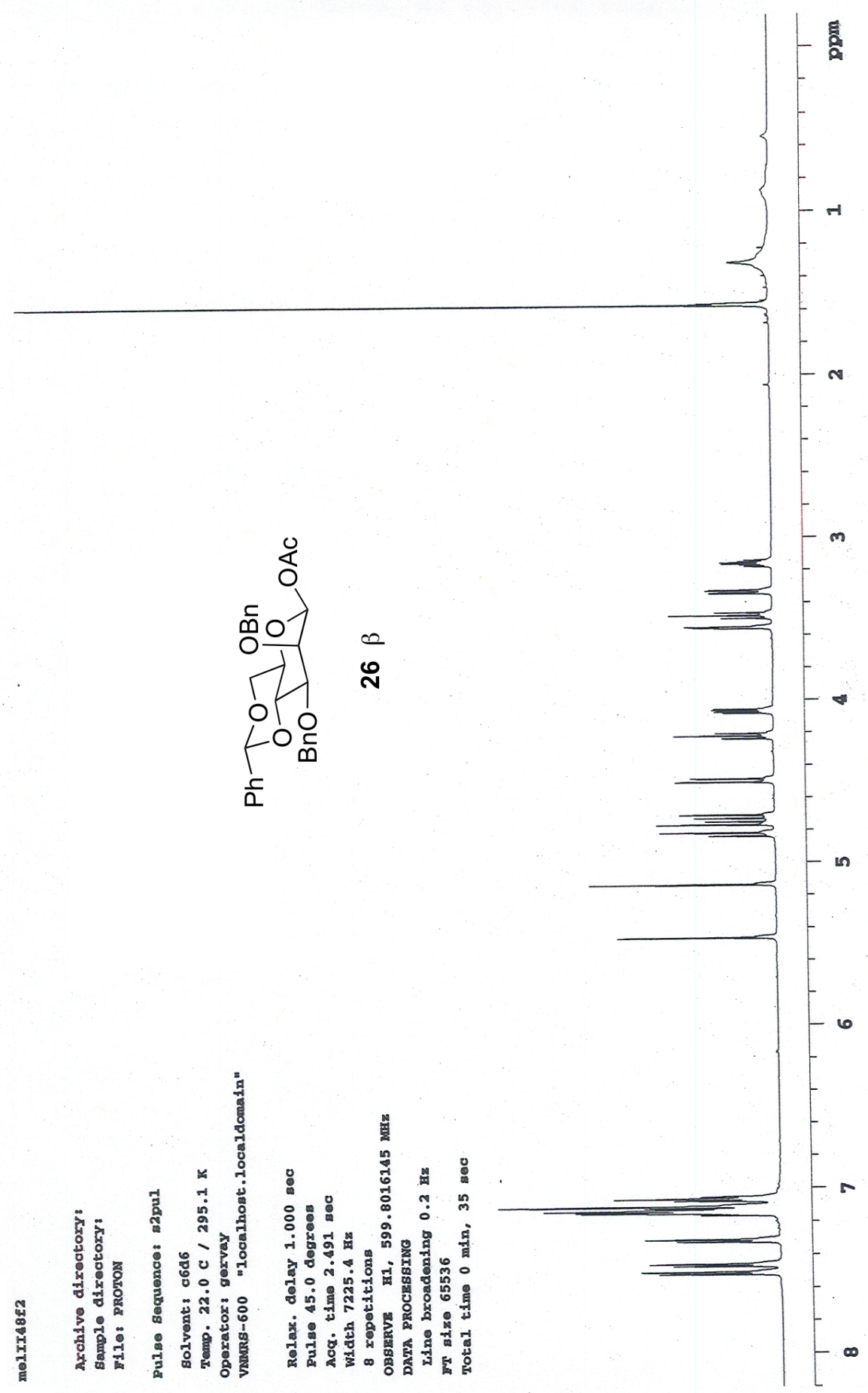




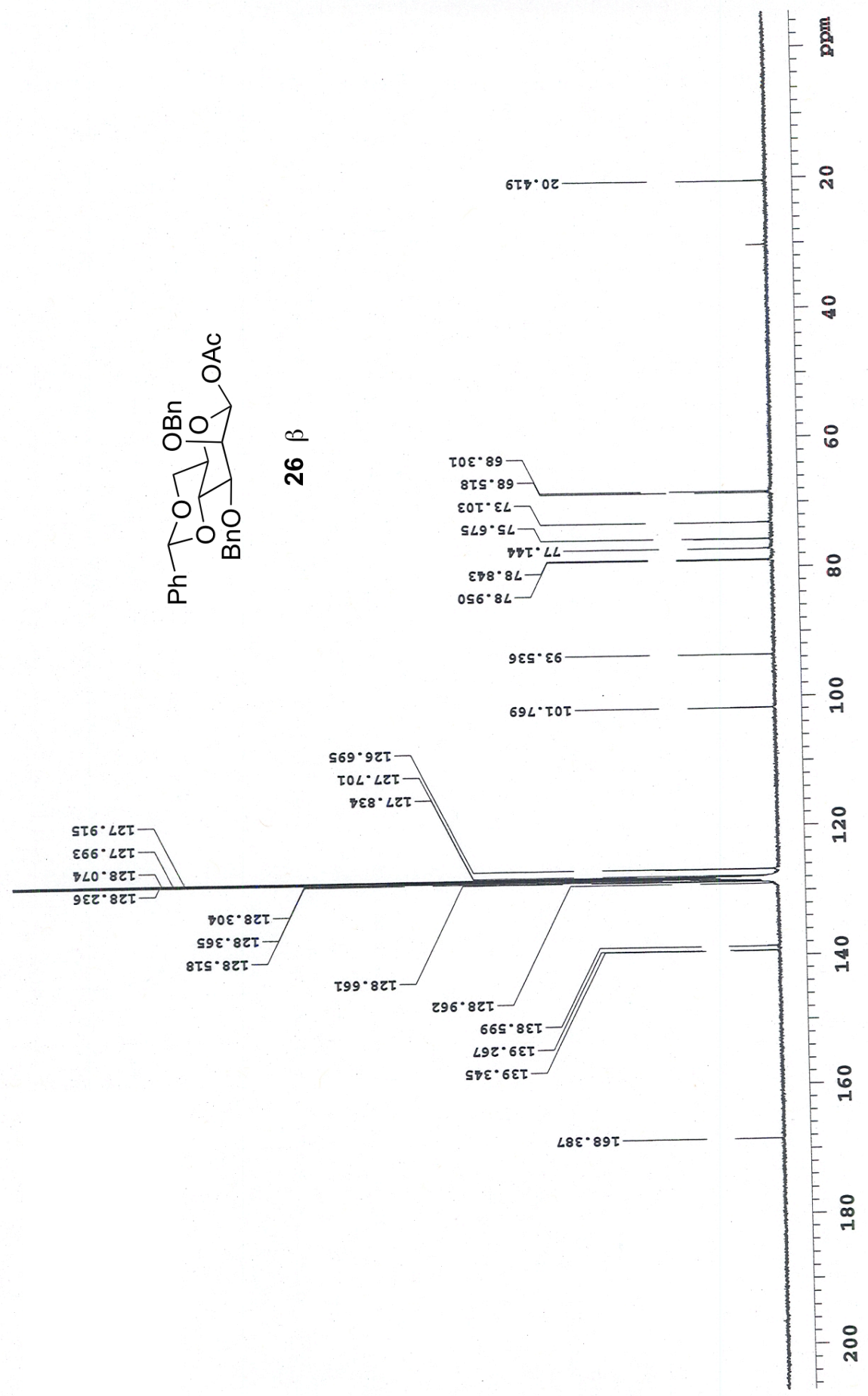




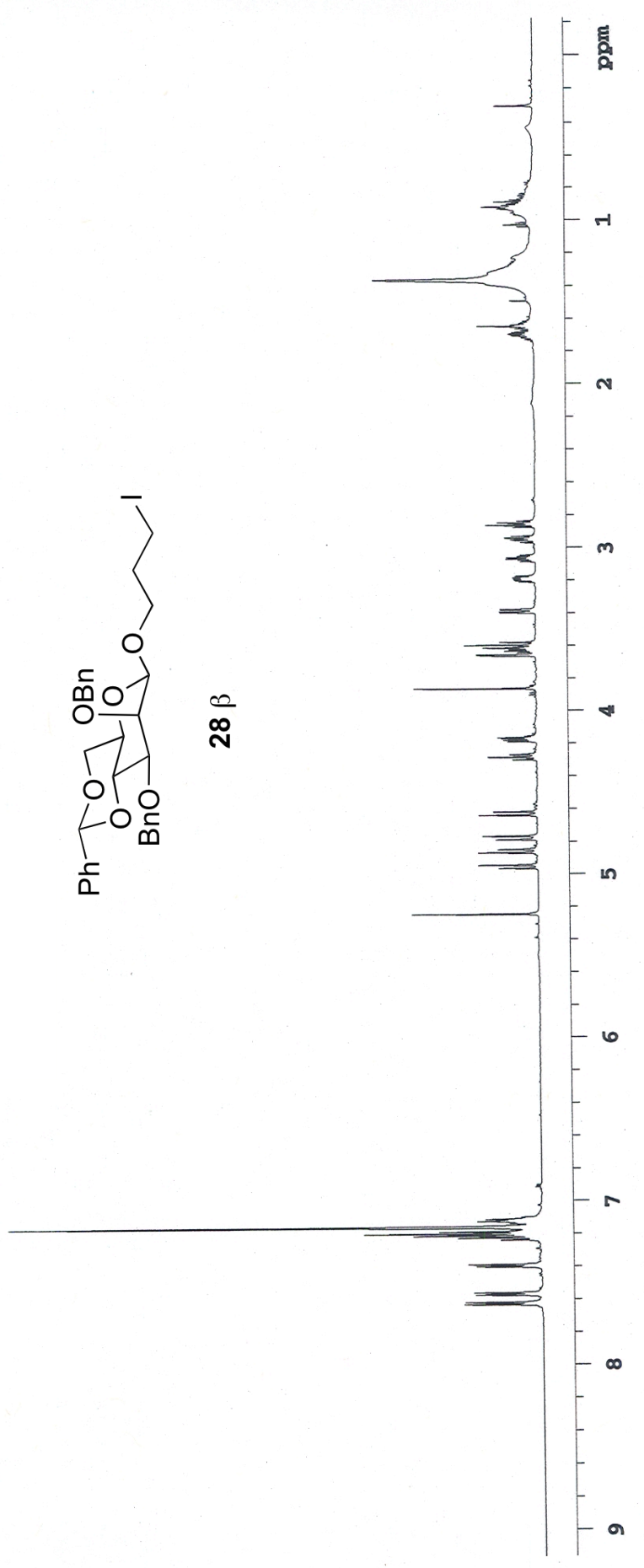




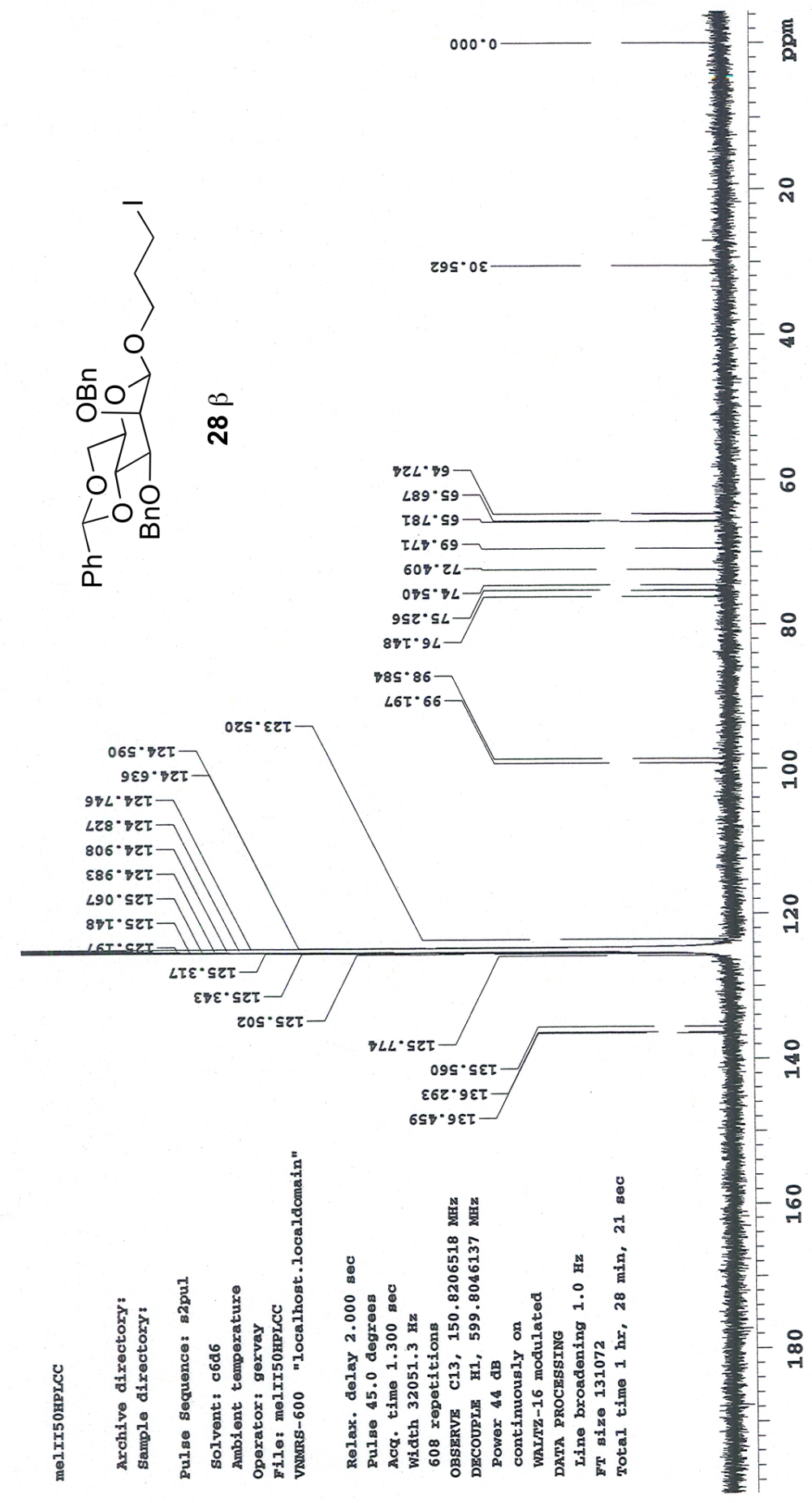




\section{Computational Section}

\section{Structure A:}

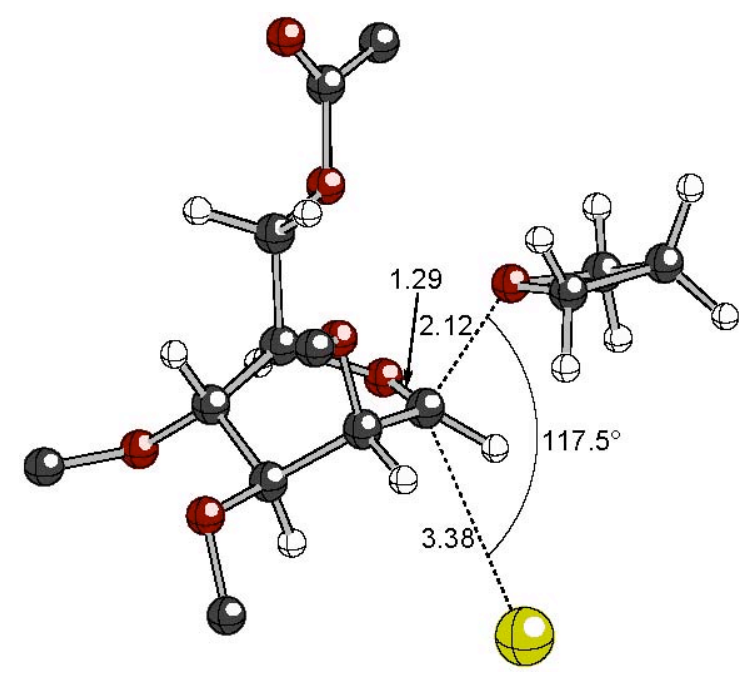

$\mathrm{HF}=-1086.4190894$ hartrees $(-681738.842789394 \mathrm{kcal} / \mathrm{mol})$ Imaginary Frequencies: $1(-79.17201 / \mathrm{cm})$

Zero-point correction $=0.391444($ Hartree $/$ Particle $)$

Coordinates:

Center Atomic Coordinates (Angstroms) Number Number X Y Z

$\begin{array}{rcr}-0.650273 & 1.804444 & 0.215486 \\ -0.560323 & 0.401536 & 0.881339 \\ -0.143356 & -0.522822 & -0.244570 \\ 1.552546 & 1.087651 & -0.874634 \\ 0.772679 & 2.232380 & -0.176273 \\ -1.273577 & 1.725963 & -0.685763 \\ 1.763833 & 1.404320 & -1.896210 \\ 1.294862 & 2.517244 & 0.747519 \\ 0.749482 & -0.134272 & -1.093722 \\ -0.841182 & -1.267158 & -0.622745 \\ -3.439598 & -0.899296 & -0.893672 \\ -1.546001 & 0.072959 & 1.228648 \\ 0.411970 & 0.373072 & 1.922194 \\ -0.085651 & 0.742373 & 3.212677 \\ -0.946877 & 0.118616 & 3.488913 \\ 0.732379 & 0.559669 & 3.912987 \\ -0.376211 & 1.796160 & 3.245064 \\ 2.839433 & 0.720151 & -0.159703 \\ 2.639884 & 0.230067 & 0.795529 \\ 3.417079 & 1.632099 & 0.023795 \\ 3.587856 & -0.155206 & -1.023701 \\ 0.801710 & 3.314894 & -1.094299 \\ -1.179931 & 2.772661 & 1.100867 \\ -2.607895 & 2.898180 & 1.046882 \\ -3.111006 & 1.947756 & 1.256014 \\ -2.877462 & 3.636904 & 1.804291 \\ -2.927494 & 3.248386 & 0.057521 \\ 0.739241 & 4.620928 & -0.520627 \\ 0.904420 & 5.318786 & -1.344042\end{array}$




$\begin{array}{rrrrr}30 & 1 & -0.231291 & 4.815357 & -0.055396 \\ 31 & 1 & 1.529996 & 4.755190 & 0.231688 \\ 32 & 6 & 4.803835 & -0.545228 & -0.561999 \\ 33 & 8 & 0.838601 & -2.100933 & 0.772288 \\ 34 & 6 & 0.893948 & -3.347414 & -0.008332 \\ 35 & 6 & 0.113377 & -2.783300 & 1.855827 \\ 36 & 6 & 0.333227 & -4.150190 & 1.180165 \\ 37 & 1 & 0.235082 & -3.290686 & -0.880830 \\ 38 & 1 & 1.919767 & -3.552196 & -0.323153 \\ & & & & \\ 39 & 1 & -0.929042 & -2.453148 & 1.889718 \\ 40 & 1 & 0.606471 & -2.600798 & 2.812818 \\ 41 & 1 & -0.568990 & -4.729080 & 0.977583 \\ 42 & 1 & 1.073053 & -4.778794 & 1.679371 \\ 43 & 8 & 5.242878 & -0.199533 & 0.515051 \\ 44 & 6 & 5.516296 & -1.417715 & -1.564370 \\ 45 & 1 & 6.340545 & -1.934560 & -1.072442 \\ 46 & 1 & 4.828701 & -2.133572 & -2.021296 \\ 47 & 1 & 5.918715 & -0.788101 & -2.365617\end{array}$

\section{IRC endpoints for Structure A:}

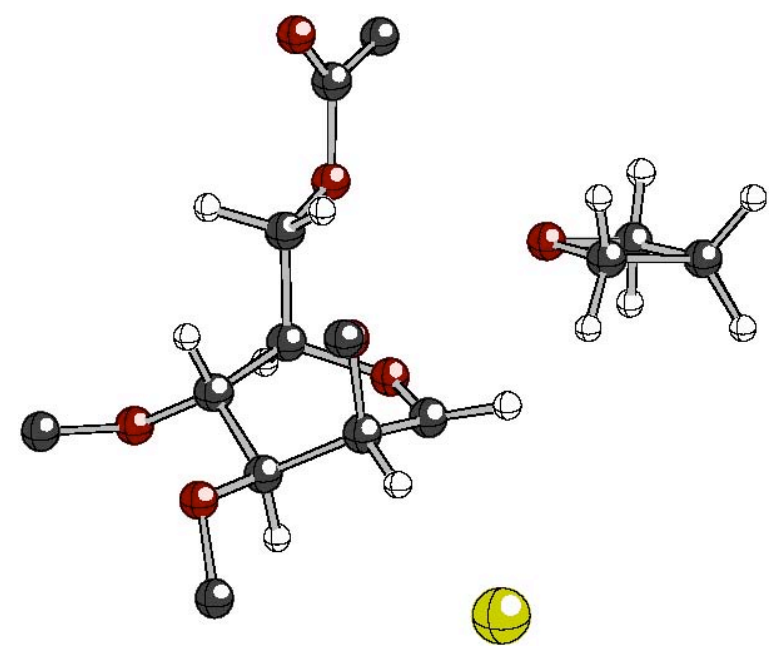

Coordinates for point 136 :

Center Atomic Coordinates (Angstroms) Number Number X Y Z

$$
\begin{array}{rcr}
-1.099416 & 1.779700 & 0.318703 \\
-0.878395 & 0.387074 & 0.937634 \\
-0.414459 & -0.535086 & -0.160533 \\
1.096761 & 1.261272 & -0.887851 \\
0.262056 & 2.324695 & -0.120797 \\
-1.752220 & 1.679103 & -0.558451 \\
1.178663 & 1.578465 & -1.927973 \\
0.798500 & 2.613474 & 0.792915 \\
0.496108 & -0.087444 & -0.989372 \\
-0.389589 & -1.603661 & -0.040391 \\
-3.039588 & -1.227125 & -1.032892 \\
-1.794019 & -0.008236 & 1.380626
\end{array}
$$




\begin{tabular}{|c|c|c|c|c|}
\hline 13 & 8 & 0.184546 & 0.407772 & 1.901622 \\
\hline 14 & 6 & -0.240016 & 0.514308 & 3.260185 \\
\hline 15 & 1 & -0.917678 & -0.308856 & 3.525638 \\
\hline 16 & 1 & 0.664383 & 0.442338 & 3.868217 \\
\hline 17 & 1 & -0.736571 & 1.472502 & 3.448191 \\
\hline 18 & 6 & 2.474135 & 1.126435 & -0.242137 \\
\hline 19 & 1 & 2.398170 & 0.600102 & 0.711604 \\
\hline 20 & 1 & 2.865619 & 2.133179 & -0.062310 \\
\hline 21 & 8 & 3.377881 & 0.429618 & -1.118496 \\
\hline 22 & 8 & 0.181118 & 3.440874 & -0.994448 \\
\hline 23 & 8 & -1.668893 & 2.683285 & 1.253755 \\
\hline 24 & 6 & -3.094301 & 2.621690 & 1.305318 \\
\hline 25 & 1 & -3.454700 & 1.620199 & 1.572828 \\
\hline 26 & 1 & -3.409436 & 3.334124 & 2.070423 \\
\hline 27 & 1 & -3.533433 & 2.901718 & 0.338762 \\
\hline 28 & 6 & 0.050585 & 4.714660 & -0.362146 \\
\hline 29 & 1 & 0.135233 & 5.456728 & -1.158579 \\
\hline 30 & 1 & -0.912718 & 4.819040 & 0.145617 \\
\hline 31 & 1 & 0.857777 & 4.873843 & 0.367507 \\
\hline 32 & 6 & 4.641670 & 0.267105 & -0.645065 \\
\hline 33 & 8 & 1.563892 & -2.378479 & 0.882112 \\
\hline 4 & 6 & 1.696088 & -3.548215 & 0.028579 \\
\hline 5 & 6 & 0.917262 & -3.158088 & 1.923328 \\
\hline 6 & 6 & 1.029563 & -4.451022 & 1.088272 \\
\hline 7 & 1 & 1.145448 & -3.423393 & -0.912201 \\
\hline 8 & 1 & 2.748004 & -3.761208 & -0.195346 \\
\hline 39 & 1 & -0.101960 & -2.804146 & 2.117978 \\
\hline 10 & 1 & 1.491030 & -3.131474 & 2.856795 \\
\hline 11 & 1 & 0.079221 & -4.899461 & 0.789840 \\
\hline 12 & 1 & 1.675898 & -5.222110 & 1.513494 \\
\hline 3 & 8 & 5.004865 & 0.676955 & 0.438501 \\
\hline 14 & 6 & 5.516599 & -0.449170 & -1.643607 \\
\hline 5 & 1 & 6.429200 & -0.781456 & -1.148588 \\
\hline 16 & 1 & 4.988838 & -1.296332 & -2.088601 \\
\hline 17 & 1 & 5.779598 & 0.240340 & -2.453398 \\
\hline
\end{tabular}

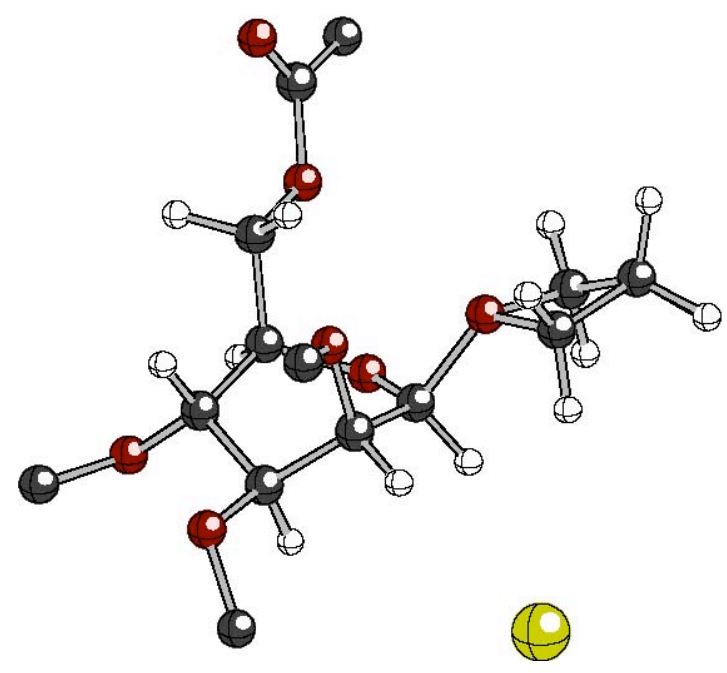

Coordinates for point 116 :

Center Atomic Coordinates (Angstroms)

Number Number X Y Z 


$\begin{array}{rcr}-0.400304 & 1.847054 & 0.095785 \\ -0.449268 & 0.519601 & 0.880323 \\ -0.090433 & -0.548875 & -0.145928 \\ 1.758704 & 0.877918 & -0.861537 \\ 1.060835 & 2.139072 & -0.278605 \\ -0.988429 & 1.724873 & -0.826069 \\ 2.050343 & 1.126744 & -1.882905 \\ 1.581620 & 2.463251 & 0.634384 \\ 0.857906 & -0.248853 & -1.061215 \\ -0.996166 & -0.924240 & -0.649445 \\ -3.587410 & -0.824151 & -0.757252 \\ -1.474022 & 0.325382 & 1.214110 \\ 0.467955 & 0.472540 & 1.970534 \\ -0.004170 & 1.063513 & 3.185915 \\ -0.975240 & 0.631549 & 3.476497 \\ 0.741362 & 0.825961 & 3.948205 \\ -0.110433 & 2.147361 & 3.090523 \\ 2.992982 & 0.460372 & -0.081415 \\ 2.742554 & 0.068122 & 0.906577 \\ 3.660467 & 1.318640 & 0.042809 \\ 3.662619 & -0.552668 & -0.863908 \\ 1.188478 & 3.140583 & -1.278136 \\ -0.909959 & 2.925992 & 0.862151 \\ -2.325912 & 3.113423 & 0.730697 \\ -2.886491 & 2.202419 & 0.969901 \\ -2.595128 & 3.910070 & 1.427388 \\ & & \\ -2.581698 & 3.416071 & -0.293022 \\ 1.158181 & 4.491004 & -0.818917 \\ 1.402032 & 5.109322 & -1.685521 \\ 0.175085 & 4.767771 & -0.427442 \\ 1.912315 & 4.654198 & -0.035247 \\ 4.850075 & -0.996827 & -0.386622 \\ 0.427119 & -1.804405 & 0.659017 \\ 0.521811 & -3.105503 & -0.090850 \\ -0.498755 & -2.460900 & 1.660950 \\ -0.086656 & -3.835474 & 1.115498 \\ -0.124043 & -3.051284 & -0.969617 \\ 1.562505 & -3.284455 & -0.357922 \\ -1.528009 & -2.166581 & 1.423424 \\ -0.190632 & -2.167576 & 2.649114 \\ -0.9134333 & -4.507405 & 0.883940 \\ 0.655639 & -4.344696 & 1.733534 \\ 5.325273 & -0.622837 & 0.666025 \\ 5.493011 & -1.973067 & -1.341203 \\ 6.252745 & -2.550390 & -0.813762 \\ 4.749743 & -2.632939 & -1.794715 \\ 5.974313 & -1.412838 & -2.150656\end{array}$

Structure B: 


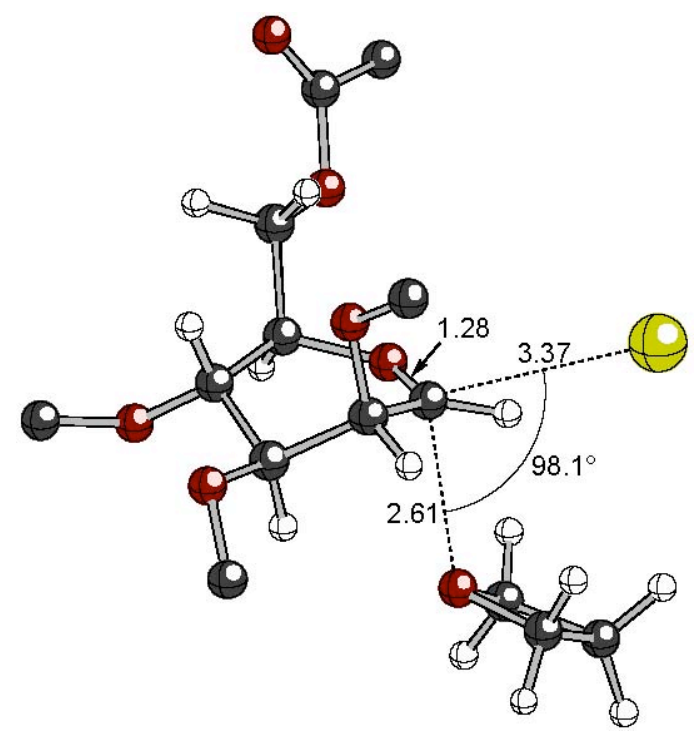

$\mathrm{HF}=-1086.4216034$ hartrees $(-681740.420349534 \mathrm{kcal} / \mathrm{mol})$

Imaginary Frequencies: $1(-53.68701 / \mathrm{cm})$

Zero-point correction $=0.390023$ (Hartree/Particle)

Coordinates:

Center Atomic Coordinates (Angstroms)

Number Number X Y Z

$\begin{array}{rrr}0.948376 & -2.177530 & -0.335800 \\ -0.101458 & -1.168049 & -0.848446 \\ -0.332708 & -0.175642 & 0.254598 \\ 2.074213 & -0.096112 & 0.652644 \\ 2.266793 & -1.420272 & -0.126856 \\ -1.050802 & -1.648230 & -1.102023 \\ 0.602475 & -2.589765 & 0.622485 \\ 2.441373 & -0.244380 & 1.669318 \\ 2.672108 & -1.203082 & -1.123100 \\ 0.665830 & 0.311965 & 0.892749 \\ -1.302109 & 0.242582 & 0.515134 \\ -3.009822 & 1.632573 & -0.711939 \\ -1.802844 & -1.275739 & 3.092215 \\ & & \\ -3.027951 & -1.992405 & 1.555662 \\ -3.328118 & -1.251328 & 2.872444 \\ -1.304471 & -0.303186 & 3.167663 \\ -1.445037 & -1.934386 & 3.891827 \\ -3.326264 & -1.473777 & 0.639677 \\ -3.331807 & -3.044625 & 1.519831 \\ -3.745548 & -0.253391 & 2.727337 \\ -3.922455 & -1.800500 & 3.605533 \\ -1.579755 & -1.888141 & 1.783309 \\ 0.454953 & -0.478673 & -1.965204 \\ -0.447664 & -0.205825 & -3.049704 \\ -1.283855 & 0.422185 & -2.723587\end{array}$




$\begin{array}{rrrrr}26 & 1 & 0.146920 & 0.321960 & -3.797325 \\ 27 & 1 & -0.818859 & -1.147468 & -3.474171 \\ 28 & 8 & 1.190819 & -3.215603 & -1.264566 \\ 29 & 8 & 3.214250 & -2.152599 & 0.636101 \\ 30 & 6 & 2.786228 & 1.070510 & -0.003185 \\ 31 & 1 & 3.825992 & 0.785744 & -0.195072 \\ 32 & 1 & 2.314404 & 1.333832 & -0.954191 \\ 33 & 8 & 2.741391 & 2.183605 & 0.900586 \\ 34 & 6 & 3.419004 & 3.295461 & 0.501657 \\ 35 & 6 & 4.104330 & -2.981786 & -0.114685 \\ 36 & 1 & 4.648323 & -2.391503 & -0.865319 \\ 37 & 1 & 4.816154 & -3.388980 & 0.606193 \\ 38 & 1 & 3.570249 & -3.794786 & -0.614721 \\ 39 & 6 & 0.266567 & -4.297500 & -1.200740 \\ 40 & 1 & 0.597894 & -5.031724 & -1.937464 \\ 41 & 1 & 0.262890 & -4.756294 & -0.202444 \\ 42 & 1 & -0.754871 & -3.982160 & -1.452107 \\ 43 & 8 & 4.067536 & 3.332998 & -0.522168 \\ 44 & 6 & 3.232928 & 4.426058 & 1.478853 \\ 45 & 1 & 3.918643 & 5.235704 & 1.229803 \\ 46 & 1 & 2.201516 & 4.789340 & 1.417806 \\ 47 & 1 & 3.401323 & 4.083078 & 2.503263\end{array}$

Optimization completed on the basis of negligible forces.

IRC

endpoints

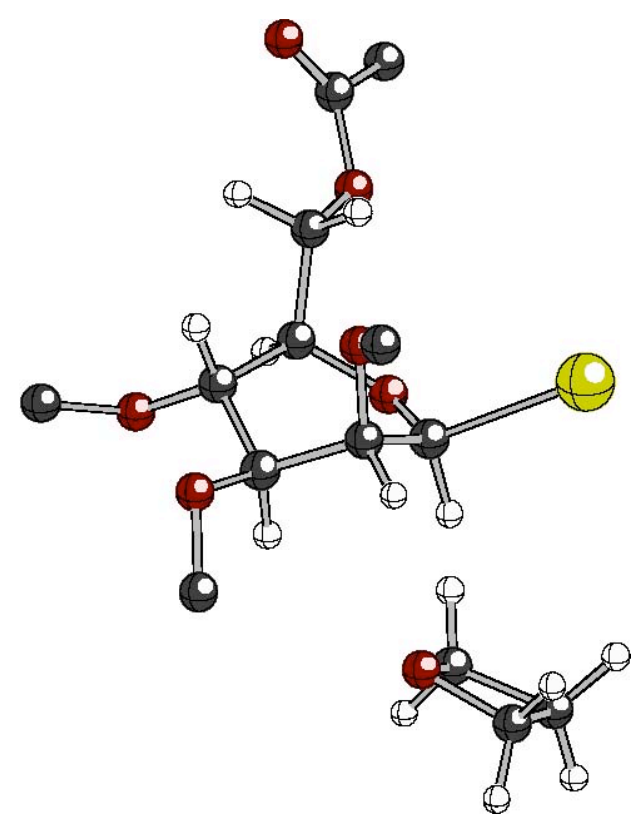

for
Structure

B:

Coordinates for point 300 :

Center Atomic

Number Number 
16

26

\section{Coordinates (Angstroms) $\mathrm{XYZ}$}

\section{$0.4246642 .098517-0.342005$ \\ $0.6979490 .783293-1.103928$}

$\begin{array}{rcr}0.717435 & -0.296182 & -0.031306 \\ -1.403499 & 0.699482 & 0.766439 \\ -1.030896 & 2.071265 & 0.132859 \\ 1.685856 & 0.806568 & -1.575816 \\ 1.086661 & 2.153708 & 0.534168 \\ -1.650277 & 0.907319 & 1.809887 \\ -1.660632 & 2.258218 & -0.745756 \\ -0.299586 & -0.235858 & 0.891800 \\ 1.665563 & -0.277647 & 0.501473 \\ 0.932913 & -2.371795 & -1.007798 \\ 3.047087 & -0.064196 & 2.973458 \\ 4.463296 & -0.189709 & 1.449892 \\ 4.174179 & -1.076310 & 2.678525 \\ 2.026751 & -0.457629 & 3.029191 \\ 3.229315 & 0.603574 & 3.824097 \\ 4.410393 & -0.673381 & 0.468162 \\ 5.378683 & 0.411431 & 1.512575 \\ 3.820330 & -2.079559 & 2.431814 \\ 4.970230 & -1.143818 & 3.423115 \\ 3.284261 & 0.624493 & 1.709786 \\ -0.319494 & 0.574694 & -2.071945 \\ 0.109131 & 0.591036 & -3.429520 \\ 0.860630 & -0.187114 & -3.615076 \\ -0.775494 & 0.380786 & -4.034415 \\ 0.509889 & 1.574598 & -3.707001 \\ 0.614847 & 3.244441 & -1.161991 \\ -1.299502 & 3.053710 & 1.129124 \\ -2.629433 & 0.080907 & 0.108287 \\ -3.380687 & 0.854626 & -0.071415 \\ -2.381027 & -0.398851 & -0.841581 \\ -3.183017 & -0.898406 & 1.013769 \\ -4.510508 & -1.147068 & 0.911549 \\ -1.721720 & 4.325634 & 0.643054 \\ -2.614289 & 4.226450 & 0.008222 \\ -1.975919 & 4.919096 & 1.524454 \\ -0.933433 & 4.826801 & 0.072135 \\ 1.951922 & 3.728729 & -1.184260 \\ 1.952909 & 4.618635 & -1.817537 \\ 2.293259 & 3.998162 & -0.175047 \\ 2.651736 & 2.993939 & -1.607301 \\ -5.238875 & -0.601012 & 0.106757 \\ -4.947683 & -2.175426 & 1.925978 \\ -6.020236 & -2.344360 & 1.831231 \\ -4.405497 & -3.112221 & 1.764281 \\ -4.709718 & -1.830557 & 2.936925\end{array}$




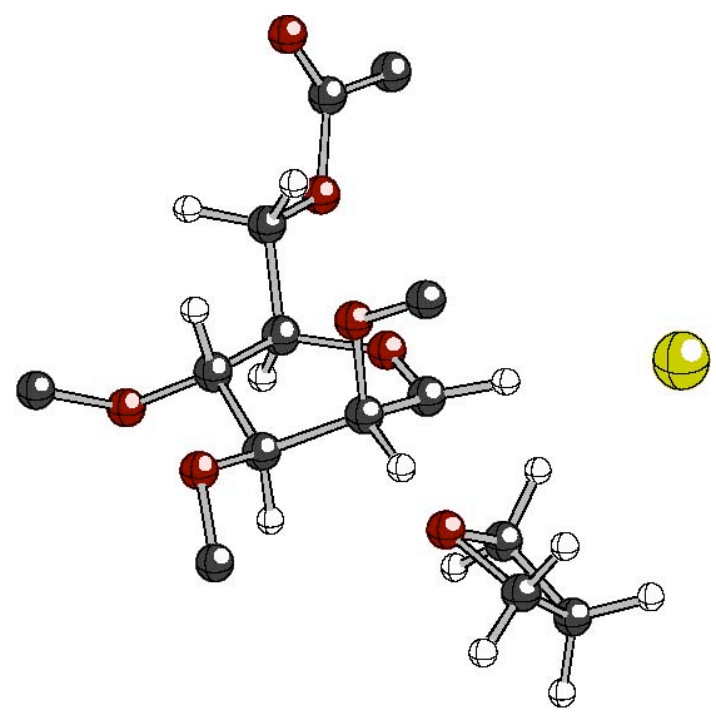

Coordinates for point 228:

\section{Center Atomic Coordinates (Angstroms)} Number Number X Y Z

$\begin{array}{rcr}1.402601 & -2.105296 & -0.106971 \\ 0.143509 & -1.436023 & -0.680201 \\ -0.271107 & -0.285206 & 0.212750 \\ 2.089092 & 0.254823 & 0.616270 \\ 2.527194 & -1.067462 & -0.059569 \\ -0.688192 & -2.146346 & -0.769067 \\ 1.186553 & -2.444634 & 0.916561 \\ 2.389914 & 0.219647 & 1.666565 \\ 2.828430 & -0.869756 & -1.096453 \\ 0.642601 & 0.531140 & 0.653042 \\ -1.245074 & 0.202517 & 0.044970 \\ -3.549533 & 0.895934 & -0.630416 \\ -1.320779 & -0.417641 & 2.881491 \\ -2.221602 & -1.917670 & 1.692579 \\ -2.637591 & -1.204507 & 2.987460 \\ -1.428139 & 0.619836 & 2.556553 \\ -0.602609 & -0.506244 & 3.698752 \\ -2.766601 & -1.580423 & 0.805328 \\ -2.088790 & -3.002788 & 1.723265 \\ -3.538037 & -0.598586 & 2.890388 \\ -2.701509 & -1.855797 & 3.863774 \\ -0.875794 & -1.260199 & 1.738782 \\ 0.459953 & -0.856531 & -1.934068 \\ -0.609099 & -0.831540 & -2.899099 \\ -1.482016 & -0.283837 & -2.524605 \\ -0.199316 & -0.326065 & -3.777951 \\ -0.893365 & -1.856073 & -3.166575 \\ 1.847631 & -3.191695 & -0.897329 \\ 3.643790 & -1.503273 & 0.701445 \\ 2.722560 & 1.437938 & -0.095352 \\ 3.803774 & 1.277119 & -0.163104 \\ 2.318413 & 1.534299 & -1.106907 \\ 2.454060 & 2.631826 & 0.653028 \\ 2.778767 & 3.800049 & 0.032973 \\ 4.681775 & -2.150282 & -0.038595 \\ 5.058328 & -1.496274 & -0.837529 \\ 5.485719 & -2.342924 & 0.674663\end{array}$




$\begin{array}{rrrrr}38 & 1 & 4.334771 & -3.091258 & -0.475464 \\ 39 & 6 & 1.151093 & -4.411313 & -0.676867 \\ 40 & 1 & 1.628167 & -5.161820 & -1.309838 \\ 41 & 1 & 1.223699 & -4.725251 & 0.374598 \\ 42 & 1 & 0.091218 & -4.340712 & -0.957892 \\ 43 & 8 & 3.326241 & 3.838108 & -1.048570 \\ 44 & 6 & 2.351338 & 4.990693 & 0.850297 \\ 45 & 1 & 2.805306 & 5.891258 & 0.441016 \\ 46 & 1 & 1.259256 & 5.082573 & 0.806126 \\ 47 & 1 & 2.630992 & 4.862657 & 1.901229\end{array}$

\section{Structure C:}

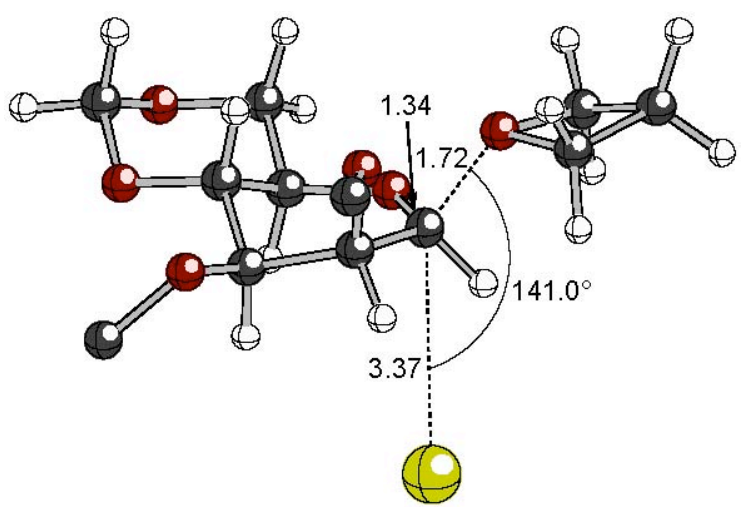

$\mathrm{HF}=-932.5336746$ hartrees $(-585174.206148246 \mathrm{kcal} / \mathrm{mol})$ Imaginary Frequencies: 1 (-159.3642 1/cm)

Zero-point correction $=0.335692$ (Hartree/Particle)

\section{Coordinates:}

Center Atomic Coordinates (Angstroms)

Number Number X Y Z

$\begin{array}{rcr}0.528356 & 0.871086 & -0.248799 \\ -1.511125 & 0.099183 & -1.325421 \\ -2.125680 & -0.050926 & 0.065948 \\ -1.089740 & -0.691854 & 0.979084 \\ 0.061425 & 0.334682 & 1.135773 \\ 1.558238 & 0.609833 & -0.504336 \\ -2.410403 & 0.931875 & 0.476039 \\ -0.669891 & -1.588831 & 0.503220 \\ 0.928454 & -0.183750 & 1.562001 \\ -1.255992 & -0.894373 & -1.708759 \\ -2.517968 & 0.765978 & -2.260069 \\ -2.159992 & 0.793581 & -3.291465 \\ -2.730241 & 1.793732 & -1.922651 \\ -0.278565 & 0.858448 & -1.318791 \\ -3.298338 & -0.849354 & -0.087256 \\ -3.706492 & -0.023746 & -2.253091 \\ -4.219856 & -0.213623 & -0.950263\end{array}$




$\begin{array}{rrrrr}18 & 1 & -5.080726 & -0.874912 & -1.044315 \\ 19 & 1 & -4.511287 & 0.761365 & -0.519846 \\ 20 & 8 & -1.589212 & -0.996410 & 2.266210 \\ 21 & 8 & -0.322366 & 1.444917 & 1.942850 \\ 22 & 6 & -2.022624 & -2.350961 & 2.425020 \\ 23 & 1 & -1.201330 & -3.049350 & 2.219300 \\ 24 & 1 & -2.330623 & -2.452025 & 3.468116 \\ 25 & 1 & -2.870527 & -2.574028 & 1.769126 \\ 26 & 6 & -0.065886 & 1.294861 & 3.343729 \\ 27 & 1 & -0.275517 & 2.269246 & 3.792746 \\ 28 & 1 & -0.711140 & 0.533871 & 3.786372 \\ 29 & 1 & 0.986080 & 1.029442 & 3.521200 \\ 30 & 53 & 2.328683 & -1.961735 & -0.555960 \\ 31 & 8 & 0.728261 & 2.565839 & -0.047557 \\ 32 & 6 & 1.356236 & 3.235970 & -1.226441 \\ 33 & 1 & 1.811902 & 2.486089 & -1.876190 \\ 34 & 1 & 0.600319 & 3.810264 & -1.760483 \\ 35 & 6 & 1.829090 & 3.051521 & 0.830145 \\ 36 & 1 & 1.400753 & 3.491788 & 1.727937 \\ 37 & 1 & 2.496208 & 2.221088 & 1.073848 \\ 38 & 6 & 2.325683 & 3.978138 & -0.292179 \\ 39 & 1 & 3.382533 & 3.887782 & -0.545887 \\ 40 & 1 & 2.069193 & 5.027360 & -0.138188\end{array}$

\section{Structure D:}

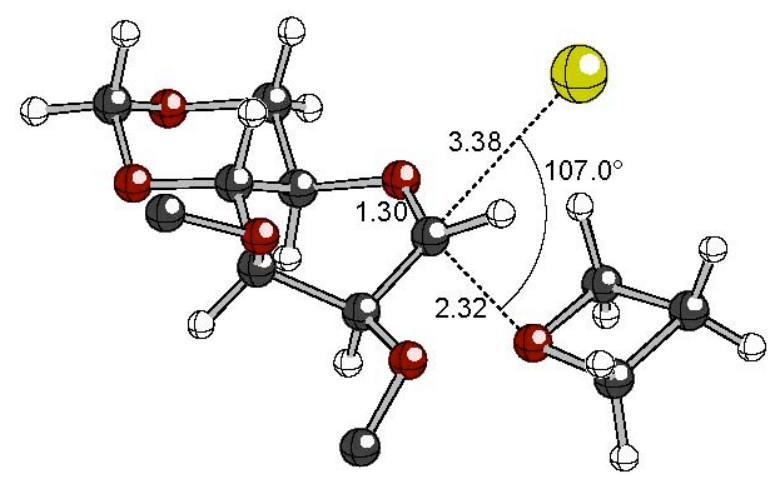

$\mathrm{HF}=-932.5337652$ hartrees $(-585174.263000652 \mathrm{kcal} / \mathrm{mol})$

Imaginary Frequencies: 1 (-61.1664 1/cm)

Zero-point correction $=0.333148$ (Hartree/Particle)

Coordinates:

Center Atomic Coordinates (Angstroms)

Number Number X Y Z

$\begin{array}{rrrrr}1 & 6 & -0.188788 & 0.593031 & -0.106873 \\ 2 & 6 & 1.816773 & 0.434555 & -1.323219 \\ 3 & 6 & 2.442680 & -0.242771 & -0.096893 \\ 4 & 6 & 1.980727 & 0.393941 & 1.226741 \\ 5 & 6 & 0.656752 & 1.206191 & 0.968248\end{array}$




$\begin{array}{rcr}-1.201660 & 0.194972 & 0.035607 \\ 2.105234 & -1.292323 & -0.091619 \\ 2.761897 & 1.097880 & 1.556708 \\ 0.982100 & 2.176889 & 0.546680 \\ 2.052083 & 1.503804 & -1.355988 \\ 2.313247 & -0.250639 & -2.594668 \\ 1.978493 & 0.264406 & -3.497005 \\ 1.959092 & -1.291815 & -2.622001 \\ 0.374863 & 0.268149 & -1.227204 \\ 3.859232 & -0.178214 & -0.231810 \\ 3.738877 & -0.189621 & -2.578531 \\ 4.284663 & -0.804442 & -1.433137 \\ 5.365597 & -0.681674 & -1.488014 \\ 4.002662 & -1.870945 & -1.408722 \\ 1.713642 & -0.551903 & 2.228088 \\ -0.154024 & 1.411850 & 2.084484 \\ 2.866224 & -1.184374 & 2.776806 \\ 3.578578 & -0.440300 & 3.162586 \\ 2.507997 & -1.809375 & 3.596288 \\ 3.379592 & -1.814445 & 2.039876 \\ 0.427646 & 2.214190 & 3.105543 \\ -0.354373 & 2.372473 & 3.849599 \\ 1.274520 & 1.705665 & 3.580547 \\ 0.752086 & 3.187618 & 2.707502 \\ -2.462457 & -1.901949 & 0.045083 \\ -1.330309 & 2.514032 & -0.742379 \\ -2.559962 & 2.686718 & 0.051234 \\ -2.551665 & 2.039315 & 0.930883 \\ -2.660662 & 3.734890 & 0.352433 \\ -2.125881 & 2.220121 & -1.943205 \\ -2.002056 & 3.022983 & -2.678123 \\ -1.838109 & 1.259749 & -2.380489 \\ -3.435540 & 2.240408 & -1.134083 \\ -3.879723 & 1.252337 & -0.999688 \\ -4.190978 & 2.955241 & -1.466610\end{array}$

Structure E:

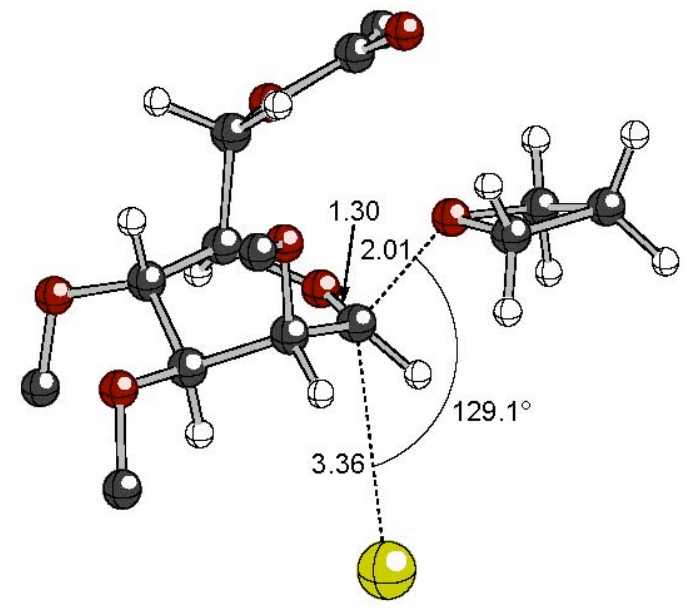

$\mathrm{HF}=-1086.4155201$ hartrees $(-681736.603017951 \mathrm{kcal} / \mathrm{mol})$ Imaginary Frequencies: 1 (-117.6666 1/cm) Zero-point correction $=0.392549$ (Hartree/Particle)

Coordinates: 
Center Atomic Coordinates (Angstroms) Number Number X Y Z

$\begin{array}{rcr}0.056579 & -0.563909 & 0.020406 \\ 1.281259 & 1.474648 & -0.511089 \\ 0.298655 & 2.312024 & 0.356776 \\ -1.025250 & 1.573361 & 0.579311 \\ -0.663846 & 0.170248 & 1.145641 \\ -0.419172 & -1.420895 & -0.449226 \\ 0.737788 & 2.474137 & 1.344411 \\ -1.573946 & 1.413664 & -0.358875 \\ -1.577984 & -0.392472 & 1.365754 \\ 1.293143 & 1.892823 & -1.518916 \\ 2.699868 & 1.479004 & 0.037898 \\ 2.815197 & 0.773487 & 0.863400 \\ 0.861675 & 0.084132 & -0.768785 \\ 0.202707 & 3.613821 & -0.198757 \\ -0.682202 & 3.788276 & -1.303429 \\ -0.487945 & 4.792040 & -1.686046 \\ -0.502316 & 3.061756 & -2.108211 \\ -1.801048 & 2.330333 & 1.485408 \\ 0.186913 & 0.258925 & 2.283251 \\ -3.213038 & 2.123903 & 1.368988 \\ -3.495907 & 1.083223 & 1.565339 \\ -3.677193 & 2.780407 & 2.107580 \\ -3.566755 & 2.388057 & 0.364846 \\ -0.494209 & 0.420525 & 3.531113 \\ 0.272419 & 0.332642 & 4.304421 \\ -0.983557 & 1.395803 & 3.600259 \\ -1.242086 & -0.373045 & 3.670225 \\ -2.957267 & -1.241359 & -1.292102 \\ 1.305744 & -1.780778 & 1.021098 \\ 1.900602 & -2.859757 & 0.206534 \\ 1.364392 & -2.963179 & -0.742560 \\ 2.956630 & -2.649226 & 0.037296 \\ 0.727413 & -2.765248 & 1.948934 \\ 0.972857 & -2.499236 & 2.978265 \\ -0.357168 & -2.828611 & 1.815553 \\ 1.525575 & -3.899139 & 1.279317 \\ 0.940589 & -4.753080 & 0.934049 \\ 2.376417 & -4.246072 & 1.868325 \\ -1.730022 & 3.720701 & -0.990249 \\ 2.937386 & 2.493111 & 0.371005 \\ 3.628915 & 1.172097 & -1.021992 \\ 4.419587 & 0.075137 & -0.913542 \\ & & \\ 4.396825 & -0.685469 & 0.032999 \\ 5.311477 & -0.058511 & -2.121762 \\ 5.969932 & -0.917563 & -1.994989 \\ 4.700861 & -0.186306 & -3.021252 \\ 5.902943 & 0.852035 & -2.255344\end{array}$

Optimization completed on the basis of negligible forces. 


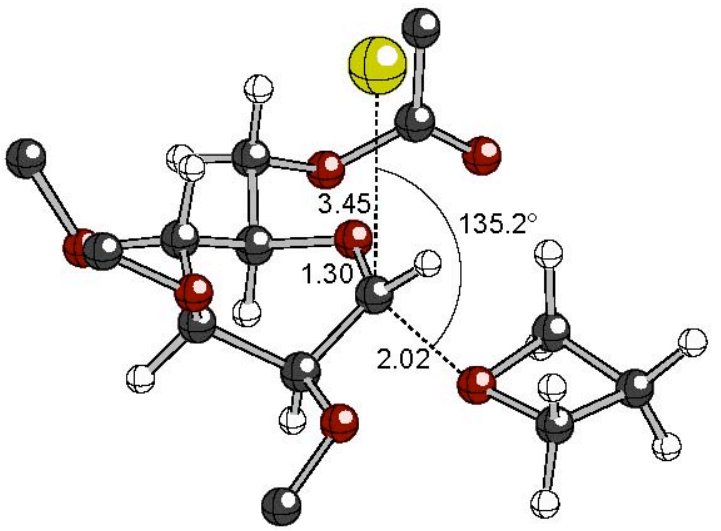

$\mathrm{HF}=-1086.4008414$ hartrees $(-681727.391986914 \mathrm{kcal} / \mathrm{mol})$

Imaginary Frequencies: 1 (-111.4525 1/cm)

Zero-point correction $=0.391839$ (Hartree/Particle $)$

Coordinates:

Center Atomic Coordinates (Angstroms)

Number Number X Y Z

$$
\begin{array}{rcr}
-0.275741 & 1.092232 & -0.023368 \\
0.024968 & -0.538877 & -1.727609 \\
1.529697 & -0.529539 & -1.374881 \\
2.022993 & 0.905458 & -1.015380 \\
0.808801 & 1.849697 & -0.730499 \\
-0.454290 & 1.161895 & 1.048629 \\
1.667893 & -1.162566 & -0.487394 \\
2.549072 & 1.280599 & -1.909443 \\
0.395818 & 2.122492 & -1.717431 \\
-0.188244 & 0.081442 & -2.605611 \\
-0.576017 & -1.926925 & -1.922894 \\
-0.373739 & -2.545613 & -1.045600 \\
-0.698504 & -0.000200 & -0.575569 \\
2.268403 & -1.002712 & -2.496018 \\
2.798568 & -2.323140 & -2.386122 \\
3.379008 & -2.494767 & -3.294737 \\
3.455051 & -2.418504 & -1.512655 \\
2.857844 & 0.974848 & 0.108761 \\
1.078995 & 3.003342 & 0.014624 \\
4.068747 & 0.235719 & 0.036835 \\
4.614498 & 0.448924 & -0.894461 \\
4.666313 & 0.548980 & 0.894457 \\
3.889433 & -0.843312 & 0.120031 \\
2.004592 & 3.901640 & -0.589801 \\
2.028141 & 4.788571 & 0.045445 \\
3.007871 & 3.464845 & -0.634033 \\
1.675514 & 4.188257 & -1.600020 \\
0.438759 & -1.186349 & 2.464656 \\
-1.810618 & 2.335457 & -0.425267 \\
-2.095917 & 3.431190 & 0.521745 \\
-1.513075 & 3.300918 & 1.437793 \\
-1.863816 & 4.393941 & 0.063308 \\
-3.144356 & 1.739597 & -0.163792
\end{array}
$$




$\begin{array}{rrrrr}34 & 1 & -3.646891 & 1.501502 & -1.101553 \\ 35 & 1 & & & \\ 36 & 6 & -3.040775 & 0.837480 & 0.443583 \\ 37 & 1 & -3.570513 & 3.000630 & 0.609417 \\ 38 & 1 & -3.962159 & 2.832951 & 1.613828 \\ 39 & 1 & -4.250221 & 3.647273 & 0.051479 \\ 40 & 1 & 2.009796 & -3.083246 & -2.318845 \\ 41 & 8 & -0.137736 & -2.388085 & -2.810747 \\ 42 & 6 & -1.975203 & -1.787162 & -2.178053 \\ 43 & 8 & -2.924781 & -1.988351 & -1.201317 \\ 44 & 6 & -4.018181 & -1.503868 & -1.391323 \\ 45 & 1 & -2.561911 & -2.823050 & 0.001651 \\ 46 & 1 & -2.117780 & -3.779099 & -0.295211 \\ 47 & 1 & -1.843640 & -2.311775 & 0.658465 \\ & 1 & -3.476941 & -3.011960 & 0.562810\end{array}$

\section{Reactant Geometries for KIE Calculations:}

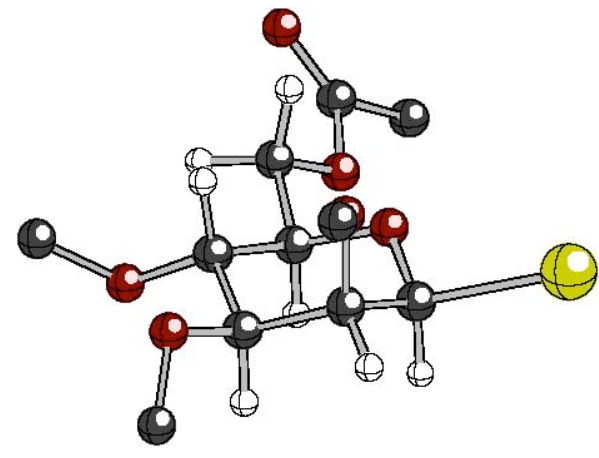

$\mathrm{HF}=-893.3306334$ hartrees $(-560573.905764834 \mathrm{kcal} / \mathrm{mol})$

Imaginary Frequencies: none

Zero-point correction $=0.302635$ (Hartree/Particle $)$

Coordinates:

Center Atomic Coordinates (Angstroms)

Number Number X Y Z

$$
\begin{array}{rcr}
-0.896608 & 1.922134 & -0.557256 \\
-1.674463 & 0.648004 & -0.132323 \\
-0.839191 & -0.547599 & -0.598129 \\
1.225942 & 0.576465 & -0.376245 \\
0.530107 & 1.901878 & 0.008905 \\
-0.811679 & 1.937325 & -1.656476 \\
1.384413 & 0.572920 & -1.466601 \\
0.481610 & 1.988663 & 1.102491 \\
0.425137 & -0.555858 & -0.003765 \\
-2.648956 & 0.621299 & -0.640548 \\
-1.834441 & 0.594632 & 1.269290 \\
-3.095442 & 1.029967 & 1.763640 \\
-3.916902 & 0.463871 & 1.301377 \\
-3.089472 & 0.827836 & 2.836969
\end{array}
$$




\begin{tabular}{|c|c|c|c|c|}
\hline 15 & 1 & -3.243914 & 2.103329 & 1.597648 \\
\hline 16 & 6 & 2.561896 & 0.423726 & 0.322690 \\
\hline 17 & 1 & 2.416273 & 0.181745 & 1.379346 \\
\hline 18 & 1 & 3.138356 & 1.347792 & 0.237743 \\
\hline 19 & 8 & 3.277782 & -0.648243 & -0.322596 \\
\hline 20 & 8 & 1.306694 & 2.952407 & -0.551770 \\
\hline 21 & 8 & -1.545106 & 3.108953 & -0.120940 \\
\hline 22 & 6 & -2.513922 & 3.621134 & -1.025785 \\
\hline 23 & 1 & -3.346289 & 2.920301 & -1.183523 \\
\hline 24 & 1 & -2.908236 & 4.536830 & -0.579706 \\
\hline 25 & 1 & -2.060051 & 3.859789 & -1.998144 \\
\hline 26 & 6 & 1.436376 & 4.118389 & 0.258916 \\
\hline 27 & 1 & 2.070272 & 4.811249 & -0.299255 \\
\hline 28 & 1 & 0.462687 & 4.580570 & 0.452104 \\
\hline 29 & 1 & 1.923401 & 3.881297 & 1.215952 \\
\hline 30 & 6 & 4.472918 & -0.979181 & 0.219483 \\
\hline 31 & 53 & -1.798931 & -2.465162 & -0.118571 \\
\hline 32 & 1 & -0.766741 & -0.560319 & -1.693943 \\
\hline 33 & 8 & 4.950721 & -0.406696 & 1.178423 \\
\hline 34 & 6 & 5.103388 & -2.134797 & -0.517803 \\
\hline 35 & 1 & 4.466318 & -3.020571 & -0.429715 \\
\hline 36 & 1 & 5.193836 & -1.900854 & -1.582783 \\
\hline 37 & 1 & 6.086084 & -2.341767 & -0.094350 \\
\hline
\end{tabular}

Optimization completed on the basis of negligible forces.

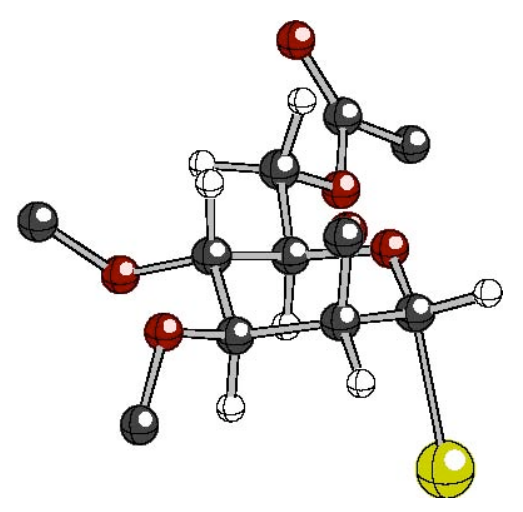

$\mathrm{HF}=-893.3401766$ hartrees $(-560579.894218266 \mathrm{kcal} / \mathrm{mol})$ Imaginary Frequencies: none Zero-point correction $=0.303111$ (Hartree/Particle)

Coordinates:

Center Atomic Coordinates (Angstroms)

Number Number X Y Z

$\begin{array}{rrrrr}1 & 6 & -1.486676 & 1.113689 & -0.352859 \\ 2 & 6 & -1.774946 & 0.221738 & 0.871292\end{array}$




$\begin{array}{rcr}-0.670328 & -0.824512 & 1.056311 \\ 0.942867 & 0.531546 & -0.094202 \\ -0.067977 & 1.686749 & -0.262747 \\ -1.540204 & 0.502486 & -1.264387 \\ 0.942408 & -0.075228 & -1.010061 \\ -0.006884 & 2.363646 & 0.600327 \\ 0.593099 & -0.323862 & 1.011804 \\ -0.783273 & -1.374779 & 1.986671 \\ -0.995696 & -2.528390 & -0.485875 \\ -2.739010 & -0.288826 & 0.761445 \\ -1.753283 & 0.989230 & 2.072818 \\ -3.030443 & 1.363627 & 2.581515 \\ -3.660916 & 0.479978 & 2.758166 \\ -2.846203 & 1.862950 & 3.535322 \\ -3.542880 & 2.053492 & 1.901958 \\ 2.344284 & 1.040791 & 0.176935 \\ 2.427521 & 1.429239 & 1.196316 \\ 2.595436 & 1.832813 & -0.532052 \\ 3.254151 & -0.063148 & 0.005409 \\ 0.284796 & 2.361642 & -1.461735 \\ -2.415673 & 2.187165 & -0.439900 \\ -3.551180 & 1.917424 & -1.253097 \\ -4.149779 & 1.081129 & -0.864203 \\ -4.164350 & 2.821415 & -1.246326 \\ -3.253763 & 1.689830 & -2.285979 \\ 0.151816 & 3.781136 & -1.425375 \\ 0.473785 & 4.144183 & -2.404021 \\ -0.885436 & 4.080070 & -1.241848 \\ 0.799330 & 4.218718 & -0.651547 \\ 4.556992 & 0.188167 & 0.273777 \\ 4.965303 & 1.275950 & 0.628206 \\ 5.399823 & -1.047446 & 0.077235 \\ 6.446007 & -0.806161 & 0.264435\end{array}$

\section{6}

1

5.069715

$-1.834428$

0.762572

37

5.277886

$-1.429107$

$-0.940946$

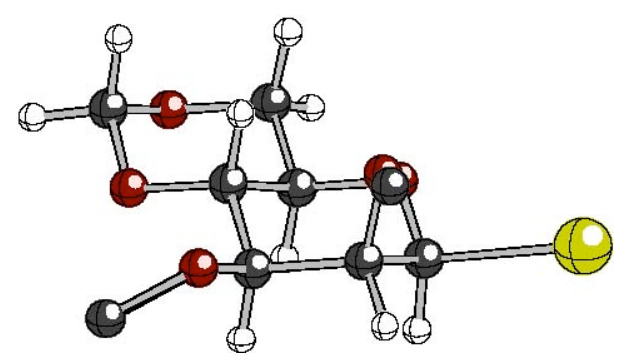

$\mathrm{HF}=-739.4555135$ hartrees $(-464015.729276385 \mathrm{kcal} / \mathrm{mol})$

Imaginary Frequencies: none

Zero-point correction $=0.245972($ Hartree/Particle $)$

Coordinates:

Center Atomic Coordinates (Angstroms)

Number Number X Y Z 


$\begin{array}{rrr}-0.782985 & -0.267033 & -0.599895 \\ 1.246791 & -1.362582 & -0.267365 \\ 1.952354 & -0.056525 & 0.136304 \\ 1.303690 & 1.121846 & -0.586510 \\ -0.212193 & 1.113570 & -0.237379 \\ 1.842156 & 0.097396 & 1.219846 \\ 1.417222 & 0.979268 & -1.674525 \\ -0.713288 & 1.873118 & -0.852882 \\ 1.359250 & -1.505516 & -1.354384 \\ 1.913986 & -2.533126 & 0.452154 \\ 1.528704 & -3.493950 & 0.105506 \\ 1.746604 & -2.449995 & 1.536854 \\ -0.138897 & -1.318423 & 0.075114 \\ 3.339096 & -0.183068 & -0.192429 \\ 3.311679 & -2.509226 & 0.149889 \\ 3.910301 & -1.280527 & 0.495376 \\ 4.955418 & -1.339600 & 0.191510 \\ 3.821262 & -1.114638 & 1.583798 \\ 1.823235 & 2.384607 & -0.213975 \\ -0.415942 & 1.361266 & 1.136621 \\ 2.956636 & 2.824396 & -0.961728 \\ 2.721854 & 2.874840 & -2.035330 \\ 3.188782 & 3.829255 & -0.601819 \\ 3.818884 & 2.167859 & -0.810646 \\ -0.762921 & 2.701580 & 1.478110 \\ -0.962887 & 2.698121 & 2.551855 \\ 0.054979 & 3.394255 & 1.255185 \\ -1.673234 & 3.015635 & 0.948217 \\ -2.922190 & -0.416191 & -0.140998 \\ -0.736933 & -0.418775 & -1.686435\end{array}$

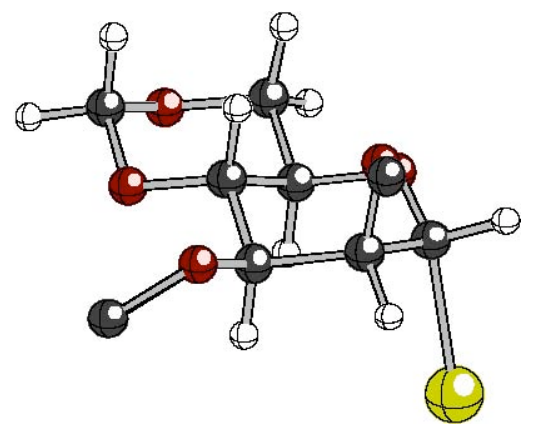

$\mathrm{HF}=-739.4652032$ hartrees $(-464021.809660032 \mathrm{kcal} / \mathrm{mol})$

Imaginary Frequencies: none

Zero-point correction $=0.246746($ Hartree/Particle $)$

Coordinates:

Center Atomic Coordinates (Angstroms)

Number Number X Y Z

$\begin{array}{rrrrr}1 & 6 & -0.957255 & 0.162828 & 1.076860 \\ 2 & 6 & 0.823494 & -1.280972 & 0.491358 \\ 3 & 6 & 1.706426 & -0.100105 & 0.059320\end{array}$




$\begin{array}{rcr}0.832319 & 0.990229 & -0.553959 \\ -0.219847 & 1.387157 & 0.505846 \\ -1.582033 & 0.436039 & 1.922883 \\ 2.223410 & 0.316889 & 0.936553 \\ 0.312100 & 0.583340 & -1.433406 \\ -0.948782 & 2.071259 & 0.057758 \\ 0.301200 & -1.680908 & -0.388046 \\ 1.702462 & -2.374178 & 1.094127 \\ 1.132775 & -3.281461 & 1.304362 \\ 2.164788 & -2.016323 & 2.027341 \\ -0.150628 & -0.873161 & 1.459360 \\ 2.670012 & -0.596944 & -0.871660 \\ 2.703279 & -2.722231 & 0.134473 \\ 3.462395 & -1.606150 & -0.273965 \\ 4.159940 & -1.957501 & -1.034101 \\ 3.998935 & -1.181938 & 0.593460 \\ 1.546671 & 2.160509 & -0.911705 \\ 0.395484 & 1.990835 & 1.639681 \\ 2.063673 & 2.169231 & -2.242471 \\ 1.254775 & 2.046881 & -2.977269 \\ 2.527992 & 3.147783 & -2.384051 \\ 2.809146 & 1.381496 & -2.389840 \\ 0.377540 & 3.418735 & 1.660851 \\ 0.801886 & 3.712853 & 2.623359 \\ 0.978975 & 3.833668 & 0.846436 \\ -0.651594 & 3.799672 & 1.592809 \\ -2.557534 & -0.518575 & -0.449193\end{array}$

